Atmos. Chem. Phys., 19, 14637-14656, 2019

https://doi.org/10.5194/acp-19-14637-2019

(C) Author(s) 2019. This work is distributed under

the Creative Commons Attribution 4.0 License.

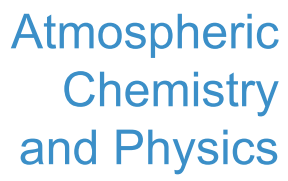

(c) (P)

\title{
Spatiotemporal variation of aerosol and potential long-range transport impact over the Tibetan Plateau, China
}

\author{
Jun Zhu ${ }^{1,2,3}$, Xiangao Xia ${ }^{2,4}$, Huizheng Che ${ }^{3}$, Jun Wang ${ }^{5}$, Zhiyuan Cong ${ }^{6}$, Tianliang Zhao ${ }^{1}$, Shichang Kang ${ }^{7,9}$, \\ Xuelei Zhang ${ }^{8}$, Xingna Yu ${ }^{1}$, and Yanlin Zhang ${ }^{1}$ \\ ${ }^{1}$ Collaborative Innovation Center on Forecast and Evaluation of Meteorological Disasters, \\ Key Laboratory for Aerosol-Cloud-Precipitation of China Meteorological Administration, \\ Nanjing University of Information Science and Technology, Nanjing, 210044, China \\ ${ }^{2}$ LAGEO, Institute of Atmospheric Physics, Chinese Academy of Sciences, Beijing, 100029, China \\ ${ }^{3}$ State Key Laboratory of Severe Weather (LASW) and Key Laboratory of Atmospheric Chemistry (LAC), \\ Chinese Academy of Meteorological Sciences, CMA, Beijing, 100081, China \\ ${ }^{4}$ University of Chinese Academy of Sciences, Beijing, 100049, China \\ ${ }^{5}$ Center of Global and Regional Environmental Research and Department of Chemical and Biochemical Engineering, \\ University of Iowa, Iowa City, Iowa, USA \\ ${ }^{6}$ Key Laboratory of Tibetan Environment Changes and Land Surface Processes, Institute of Tibetan Plateau Research, \\ Chinese Academy of Sciences, Beijing, 100101, China \\ ${ }^{7}$ State Key Laboratory of Cryospheric Science, Northwest Institute of Eco-Environment and Resources, \\ Chinese Academy of Sciences, Lanzhou, 730000, China \\ ${ }^{8}$ Northeast Institute of Geography and Agroecology, Chinese Academy of Sciences, Changchun, 130102, China \\ ${ }^{9}$ CAS Center for Excellence in Tibetan Plateau Earth Sciences, Beijing, China
}

Correspondence: Jun Zhu (junzhu@nuist.edu.cn) and Xiangao Xia (xxa@mail.iap.ac.cn)

Received: 19 May 2019 - Discussion started: 12 June 2019

Revised: 26 October 2019 - Accepted: 30 October 2019 - Published: 4 December 2019

\begin{abstract}
The long-term temporal-spatial variations in the aerosol optical properties over the Tibetan Plateau (TP) and the potential long-range transport from surrounding areas to the TP were analyzed in this work, by using multiple years of sun photometer measurements (CE318) at five stations in the TP, satellite aerosol products from the Moderate Resolution Imaging Spectroradiometer (MODIS) and CloudAerosol Lidar with Orthogonal Polarization (CALIOP), back-trajectory analysis from the Hybrid Single Particle Lagrangian Integrated Trajectory (HYSPLIT) and model simulations from the Goddard Earth Observing System (GEOS)Chem chemistry transport model. The results from the ground-based observations showed that the annual aerosol optical depth (AOD) at $440 \mathrm{~nm}$ at most TP sites increased in recent decades with trends of $0.001 \pm 0.003 \mathrm{yr}^{-1}$ at Lhasa, $0.013 \pm 0.003 \mathrm{yr}^{-1}$ at Mt_WLG, $0.002 \pm 0.002 \mathrm{yr}^{-1}$ at NAM_CO and $0.000 \pm 0.002 \mathrm{yr}^{-1}$ at QOMS_CAS. The increasing trend was also found for the aerosol extinction
\end{abstract}

Ångström exponent (EAE) at most sites with the exception of the Mt_WLG site. Spatially, the AOD at $550 \mathrm{~nm}$ observed from MODIS showed negative trends at the northwest edge close to the Taklimakan Desert and to the east of the Qaidam Basin and slightly positive trends in most of the other areas of the TP. Different aerosol types and sources contributed to a polluted day (with CE318 AOD at $440 \mathrm{~nm}>0.4$ ) at the five sites on the TP: dust was the dominant aerosol type in Lhasa, Mt_WLG and Muztagh with sources in the Taklimakan Desert, but fine-aerosol pollution was dominant at NAM_CO and QOMS_CAS with transport from South Asia. A case of aerosol pollution at Lhasa, NAM_CO and QOMS_CAS during 28 April-3 May 2016 revealed that the smoke aerosols from South Asia were lifted up to $10 \mathrm{~km}$ and transported to the TP, while the dust from the Taklimakan Desert could climb the north slope of the TP and then be transported to the central TP. The long-range transport of 
aerosol thereby seriously impacted the aerosol loading over the TP.

\section{Introduction}

The heavy haze that has occurred in recent years in China has been largely attributed to the atmospheric aerosols (Zhang et al., 2015). In addition, atmospheric aerosols can affect the climate through the interactions between aerosol and radiation and between aerosol and cloud (Takemura et al., 2005; Li et al., 2017; Huang et al., 2006a, b; Liu et al., 2011, 2014), while the clouds and their precipitation are also connected to large-scale atmospheric circulations (Yang et al., 2010, 2017a). However, there is still a high level of uncertainty about the impact of aerosols on the climate, which is mostly due to the high spatiotemporal variability of aerosols (IPCC, 2013). Therefore, studying the physical and chemical properties of aerosols over different regions is essential.

The Tibetan Plateau (TP) is the largest elevated plateau in East Asia and considered one of the most pristine terrestrial regions, along with the Arctic and Antarctic. However, in the past two decades, the TP has been surrounded by an unprecedented growth of emissions of Asian air pollutants from various sources. Consequently, some studies have demonstrated that the aerosols transported from its surrounding areas (South Asia and Taklimakan Desert) have polluted the TP (Huang et al., 2007; Xia et al., 2011; Kopacz et al., 2011; Lu et al., 2012; Liu et al., 2015; Zhu et al., 2018; Jia et al., 2015, 2019). The increase in aerosols over the TP may have an important impact on the regional or global climate. Lau et al. (2006) has suggested that increased absorbing aerosols (dust and black carbon) over the TP may create a positive tropospheric temperature anomaly over the TP and adjacent regions to the south, causing the advance and enhancement of the Indian summer monsoon. Besides the impact of aerosols over the TP on the radiation budget, temperature and Indian summer monsoon, Liu et al. (2019a) reported a potential relationship may exist between the aerosol index and ice cloud properties over the TP, in which the aerosols have a more dominant influence than meteorological conditions on ice cloud properties (except for the nocturnal ice cloud droplet radius and ice water path during the daytime). Furthermore, Liu et al. (2019b) found the effect of the dust aerosols over the TP on the development of convective clouds and then movement of the some developed convective clouds could induce significant precipitation over the Yangtze River basin and North China. Attempts have been made to reveal the linkages between climate change (such as changes to glaciers and monsoons) and the air pollutants around the TP (mainly absorbing carbonaceous materials) (Qian et al., 2011; Wang et al., 2016; Lee et al., 2013; Jia et al., 2018). However, the quantitative effect of the TP aerosol on climate variability remains largely unknown, and it is very essential to fully understand the aerosol characteristics over the TP.

A large amount of attention has been paid to aerosol characteristics over the TP (Wan et al., 2015; Tobo et al., 2007; Zhao et al., 2013; Liu et al., 2008; Du et al., 2015). Although the seasonal variations in aerosol properties over the TP have been analyzed based on ground-based observations or satellite products (Shen et al., 2015; Xia et al., 2008), analysis is needed of the long-term trends in the variation of aerosols over the TP to provide predictions and guidelines for environment policies. In past studies, spring or summer have often been studied due to the important impacts of dust and carbonaceous aerosols (Huang et al., 2007; Cong et al., 2007; Lee et al., 2013). However, most studies of the aerosol properties based on ground-based measurements have been conducted at a single site over the TP, such as NAM_CO (Cong et al., 2009), Mt_Yulong (Zhang et al., 2012) and Mt_WLG (Che et al., 2011). Past studies have mostly focused on single stations or short-term variations due to the difficulty of taking a sufficient number of ground-based observations in challenging weather conditions over the remote plateau.

Ground-based measurements can offer more accurate data on aerosol properties, while large-scale spatial observations of aerosol optical and physical properties require satellite remote-sensing methods ( $\mathrm{Li}$ et al., 2015, 2018; Xing et al., 2017). Thus, the long-term detection of aerosols from both ground and satellite platforms is absolutely necessary for improving our understanding of the climate effects of aerosol over the TP region. Consequently, based on multiple years of observations from five ground-based sun photometers at the TP and the MODIS aerosol optical depth product over the TP region, our work here is focused on the long-term spatiotemporal variations in the aerosol optical properties over the TP and the aerosol properties and sources during the high aerosol loading over the TP. In addition, we also combined the observation and models to study the aerosol transport process over the TP, thereby helping to reduce the uncertainties in estimating aerosol radiative forcing and aerosol sources.

In this paper, Sect. 2 describes the observation sites, data and methods. The results of the analysis of the spatiotemporal variations in aerosol properties over the TP are shown in Sect. 3. The analysis of aerosol high loading and an aerosol transport case are presented in Sects. 4 and 5, respectively. The conclusions are presented in Sect. 6 .

\section{Site, data and methodology}

\subsection{Sites}

In this study, five sites in the TP equipped with sun- and sky-scanning radiometers (CE318) were used (Fig. 1). Table 1 shows the station locations and descriptions. The Lhasa station is the only urban site that suffers from local anthropogenic emissions. For the other four sites, local anthro- 


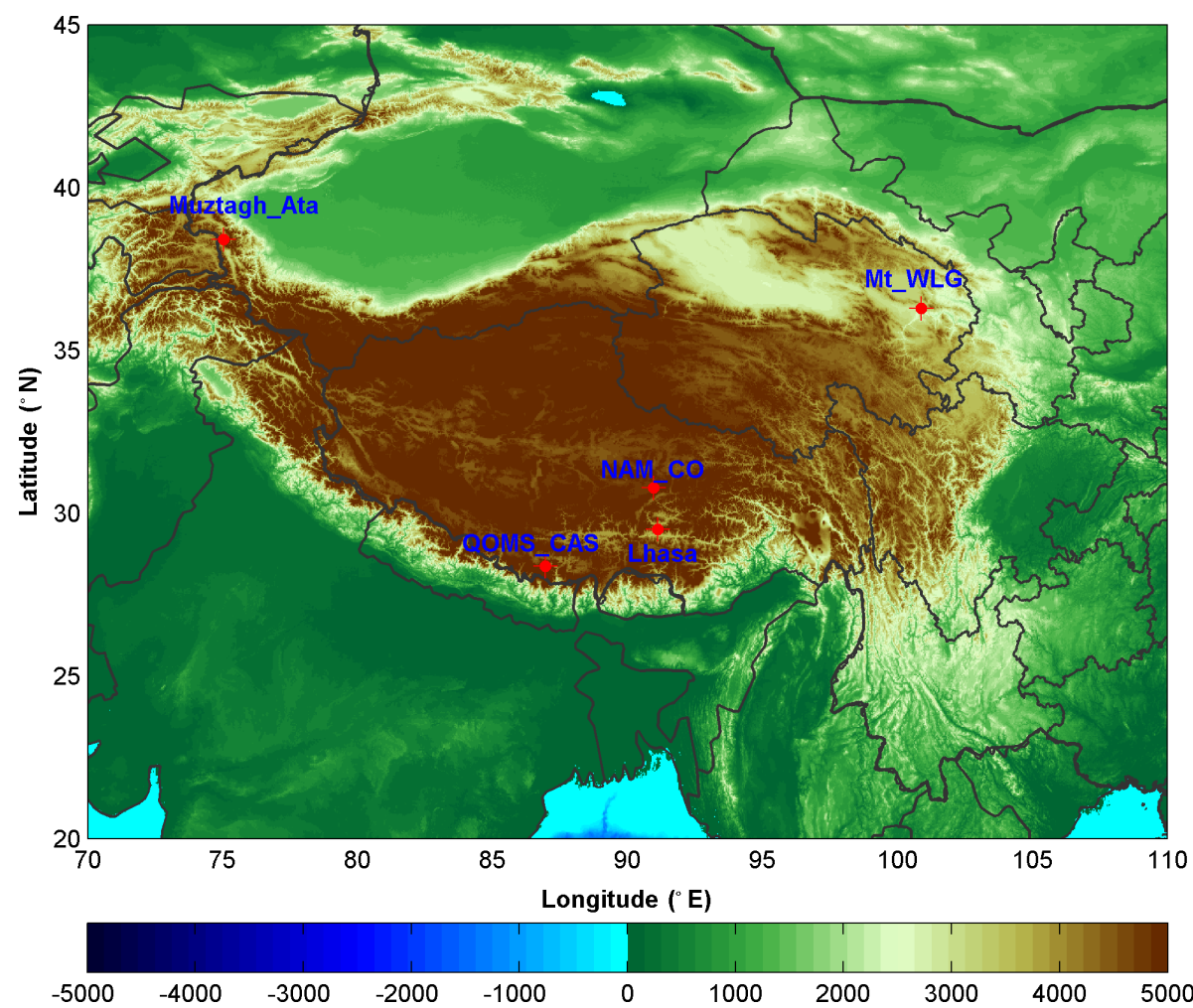

Figure 1. Topography of the Tibetan Plateau (TP) and the five CE318 stations located in the TP (Lhasa, Mt_WLG, Mutztagh_Ata, NAM_CO and QOMS_CAS).

Table 1. Site location and description.

\begin{tabular}{lrrl}
\hline Site name & Lat $\left({ }^{\circ} \mathrm{N}\right)$ & Long $\left({ }^{\circ} \mathrm{E}\right)$ & Site description, observation days and period \\
\hline Lhasa & 29.50 & 91.13 & Urban station on the Tibetan Plateau, 3648 m a.s.1., 1554 d, May 2007-Dec 2017 \\
Mt_WLG & 36.28 & 100.90 & Mountain, 3816 m a.s.1., 314 d, Sep 2009-Jul 2013 \\
Muztagh_Ata & 38.41 & 75.04 & Mountain, 3674 m a.s.1., 84 d, Jun-Oct 2011 \\
NAM_CO & 30.77 & 90.96 & Mountain, 4746 m a.s.1., 1061 d, Aug 2006-Aug 2016 \\
QOMS_CAS & 28.36 & 86.95 & Mountain, 4276 m a.s.1., 1623 d, Oct 2009-Nov 2017 \\
\hline
\end{tabular}

pogenic emissions are extremely rare due to the low number of human inhabitants. However, Mt_WLG is in the northeast of the TP, where it is situated on the dust transport path from the largest desert in China (the Taklimakan Desert). The Muztagh_Ata site is located in the northwest corner of the TP and next to the Central Asian desert and the Taklimakan Desert. NAM_CO is located on the central Tibetan Plateau, $220 \mathrm{~km}$ away from Lhasa. QOMS_CAS is located at the northern slope of Mt. Qomolangma on the border of Tibet and Nepal. Therefore, these five sites are representative of the spatial features of the TP.

\subsection{Data}

\subsubsection{CE318 aerosol optical properties}

The column-integrated aerosol properties over the five TP sites are derived from CE318 measurements. Table 1 shows the observation period. The CE318 instrument measures direct solar spectral radiation and the angular distribution of sky radiance. These spectral radiances can be used to retrieve aerosol optical parameters (such as aerosol optical depth - AOD) based on Beer's law and aerosol microphysical properties (such as volume size distribution) and the radiative forcing through radiation transfer theory (Dubovik and King, 2000; Dubovik et al., 2006). The instruments were periodically calibrated using the Langley method at AERONET global calibration sites (Izaña, Spain; or Mauna Loa, USA) or using the intercomparison calibra- 
tion method at the Beijing-CAMS site (Che et al., 2015). The cloud-screened and quality-controlled data of AOD, extinction Ångström exponent (EAE), and aerosol volume size distribution $(\mathrm{d} V(r) / \mathrm{d} \ln r)$ are used in this work (Giles et al., 2019). Eck et al. (1999) showed that the uncertainty of the AOD was approximately 0.01 to 0.02 . The EAE was calculated from the AOD at 440 and $870 \mathrm{~nm}$. The errors of retrieval for $\mathrm{d} V(r) / \mathrm{d} \ln r$ were less than $10 \%$ in the maxima of the $\mathrm{d} V(r) / \mathrm{d} \ln r$ and may increase up to $35 \%$ for the minimum values of $\mathrm{d} V(r) / \mathrm{d} \ln r$ within the radius range between 0.1 and $7 \mu \mathrm{m}$; for the edges of the retrieval size, the errors increased apparently but did not significantly affect the derivation of the main feature of $\mathrm{d} V(r) / \mathrm{d} \ln r$ (Dubovik et al., 2002).

\subsubsection{The MODIS AOD product}

The Moderate Resolution Imaging Spectroradiometer (MODIS) instrument is a multispectral sensor with a wide spectral range from 0.4 to $14.4 \mu \mathrm{m}$ in 36 wavelength bands, on board the Terra (morning descending direction) and Aqua (afternoon ascending direction) satellites in polar orbit. Its broad swath of $2330 \mathrm{~km}$ permits retrieval aerosol products to cover the global word within 1-2 d. In this study, both the Terra and Aqua MODIS Collection 6 Deep Blue (DB) and Dark Target (DT) combined AOD at $550 \mathrm{~nm}$ products with $10 \mathrm{~km}$ spatial resolution (Levy et al., 2013) from 2006 to 2017 were used. The combined MODIS DT and DB AOD at $550 \mathrm{~nm}$ (MODIS_AOD) merges the products from the two algorithms based on the normalized difference vegetation index (NDVI) statistics as follows: (1) the DT AOD data are used for NDVI $>0.3$, (2) the DB AOD data are used for NDVI $<0.2$, and (3) the mean of both the algorithms or AOD data with a high-quality flag is used for $0.2 \leq \mathrm{NDVI} \leq 0.3$. The MODIS_AOD had been validated in the global or regional areas (Bilal et al., 2018; Ma et al., 2016; Sayer et al., 2014). The root-mean-square error (RMSE) of MODIS_AOD was approximately 0.13, and the percentage of MODIS_AOD data within the expected error was more than $71 \%$ at the Kunming site, which is near the TP (Zhu et al., 2016).

\subsubsection{The CALIOP profile data}

The Cloud-Aerosol Lidar with Orthogonal Polarization (CALIOP), the primary instrument on board the CALIPSO satellite, is a near-nadir-viewing two-wavelength (532 and $1064 \mathrm{~nm}$ ) polarization-sensitive lidar that performs global vertical profile measurements of aerosols and clouds (Winker et al., 2010). It provides three primary calibrated and geolocated profile products: total attenuated backscatter at 532 and $1064 \mathrm{~nm}$ and the perpendicular polarization component at $532 \mathrm{~nm}$. The CALIOP products (version 4.10) used in this study include the attenuated backscattering coefficient profiles from Level $1 \mathrm{~B}$ and the vertical feature mask data products of aerosol subtype from Level 2 products under $15 \mathrm{~km}$ altitude, which were downloaded from the Langley Atmospheric Science Data Center (ASDC). Kumar et al. (2018) had shown that the AOD from CALIOP version 4.10 agreed with the ground-based CE318 observation at a site in the central Himalayas with a correlation $>0.9$, and $\sim 87 \%$ of the matchup data were within the expected error limits.

\subsection{Methodology}

The ground-based CE318 observations and MODIS AOD products were analyzed to show the spatiotemporal variations in aerosol properties in the TP.

The CE318-observed AOD at $440 \mathrm{~nm}$ with values larger than 0.4 at each site was specially analyzed to study the aerosol properties of the high aerosol loading over the TP. The value of 0.4 was selected because the mean annual values of AOD observed by CE318 instruments at the TP sites were less than $\sim 0.1$ in the past studies (Xia et al., 2016; Cong et al., 2009), and this value is normally regarded as the high aerosol loading (Eck et al., 2010; Giles et al., 2012). Back trajectories were used for the aerosol source analysis in the TP. The back trajectories on the high aerosol loading days were calculated by using the Hybrid Single Particle Lagrangian Integrated Trajectory (HYSPLIT) model which was driven by the $1^{\circ}$ horizontal resolution archived meteorological fields (Draxler and Hess, 1998). Back trajectories of $72 \mathrm{~h}$ ending at the five sites at $10 \mathrm{~m}$ a.g.l. (above ground level) at 12:00 UTC on the days with high aerosol loading (CE318 AOD at $440 \mathrm{~nm}>0.4$ ) were used to identify the air mass sources.

A case of long-range aerosol transport to the TP was selected based on the ground CE318 observations over Lhasa, NAM_CO and QOMS_CAS. The HYSPLIT back trajectories and the MODIS and CALIOP products were used to show the potential aerosol sources, spatial aerosol loading and the vertical features of the aerosol over the TP during the case period. In addition, the Goddard Earth Observing System (GEOS)-Chem chemistry transport model was used to simulate the AOD and its components (dust and carbon aerosols) during the case period, which may reflect the change in aerosol type during the case period.

The GEOS-Chem chemical transport model (version 11$01)$ coupled with the online radiative transfer calculations $(\mathrm{RRTMG})$ at $0.5^{\circ} \times 0.667^{\circ}$ horizontal resolution over the East Asia domain (Bey et al., 2001; Wang et al., 2004) was used. The model was driving by the Global Modeling and Assimilation Office (GMAO) MERRA-2 meteorology with the temporal resolution of $3 \mathrm{~h}$ for meteorological parameters and $1 \mathrm{~h}$ for surface fields. The simulation type of full chemistry in the troposphere was selected. The implementation of RRTMG in GEOS-Chem was described in Heald et al. (2014). The AOD was calculated according to Martin et al. (2003). The default global anthropogenic emissions were 
Table 2. Seasonal aerosol optical depth $\left(\mathrm{AOD}_{440 \mathrm{~nm}}\right)$ and extinction Ångström exponent (EAE $\left.440-870 \mathrm{~nm}\right)$ from CE318 at the five sites in the TP.

\begin{tabular}{|c|c|c|c|c|c|c|c|c|}
\hline \multirow[t]{2}{*}{ Site } & \multicolumn{4}{|c|}{ AOD } & \multicolumn{4}{|c|}{ EAE } \\
\hline & MAM & JJA & SON & DJF & MAM & JJA & SON & DJF \\
\hline Lhasa & $0.16+0.10$ & $0.12+0.08$ & $0.10+0.18$ & $0.09+0.08$ & $0.72+0.37$ & $0.97+0.40$ & $1.11+0.38$ & $0.91+0.52$ \\
\hline Mt_WLG & $0.13+0.16$ & $0.14+0.07$ & $0.08+0.11$ & $0.08+0.07$ & $0.37+0.38$ & $0.65+0.40$ & $1.04+0.80$ & $0.58+0.69$ \\
\hline Muztagh_Ata & $\mathrm{NaN}$ & $0.14+0.06$ & $0.14+0.05$ & $\mathrm{NaN}$ & $\mathrm{NaN}$ & $0.73+0.30$ & $0.64+0.27$ & $\mathrm{NaN}$ \\
\hline NAM_CO & $0.07+0.07$ & $0.06+0.04$ & $0.03+0.05$ & $0.03+0.01$ & $0.63+0.44$ & $0.62+0.45$ & $0.65+0.32$ & $0.78+0.43$ \\
\hline QOMS_CAS & $0.08+0.06$ & $0.06+0.04$ & $0.03+0.01$ & $0.03+0.02$ & $1.04+0.38$ & $0.76+0.43$ & $0.85+0.51$ & $1.10+0.67$ \\
\hline
\end{tabular}

overwritten over East Asia by the MIX inventory from Li et al. (2014). The Global Fire Emission Database (GFED) (van der Werf et al., 2010) has been used to specify emissions from fire. More details on the model and the other emissions data used and the evaluation of AOD in the east and south of the TP were shown in Zhu et al. (2017).

In this study, the AOD values from the CE318, MODIS, and GEOS-Chem model were used. For convenience, CE318_AOD, MODIS_AOD and Model_AOD stand for the AOD observed by CE318, MODIS and the AOD simulated by the GEOS-Chem model, respectively. For CE318_AOD, the $440 \mathrm{~nm}$ wavelength is often studied, while MODIS_AOD and Model_AOD generally use the data at $550 \mathrm{~nm}$ wavelength. Thus, unless otherwise specified, CE318_AOD, MODIS_AOD and Model_AOD hereinafter represent the ones at 440,550 and $550 \mathrm{~nm}$, respectively.

\section{Temporal-spatial variations in aerosol properties}

\subsection{Aerosol properties observed by the CE318 instruments}

The monthly, seasonal, and annual variations in aerosol properties observed from the CE318 instruments at the five TP sites were analyzed.

The monthly variations in CE318_AOD and EAE at the five sites over the TP are shown in Fig. 2. The monthly mean CE318_AOD was highest in April at the Lhasa (0.19), NAM_CO (0.09) and QOMS_CAS (0.10) sites, while the value at Mt_WLG was highest in June (0.20). The monthly mean CE318_AOD rapidly increased from January to April and then slightly decreased until December at the Lhasa, NAM_CO and QOMS_CAS sites. However, the monthly mean CE318_AOD at Mt_WLG was nearly symmetrical from January to December. The monthly variation in EAE was different from the AOD. The highest monthly mean values of EAE occurred in September at Lhasa (1.15), October at Mt_WLG (1.15), and in January at the NAM_CO (0.93) and QOMS_CAS (1.17) sites. The EAE at QOMS_CAS also showed a high value of 1.17 in April, which may be caused by the smoke aerosol transported from South Asia during this period. The monthly mean EAE first decreased from January to March and then increased until September at Lhasa. The monthly mean EAE values at NAM_CO also decreased from January to March but did not increase apparently in the following months. The EAE at Mt_WLG decreased from January to May and then increased obviously from May to October. The Lhasa, NAM_CO, and QOMS_CAS sites are near and located in the south of the TP. Thus, the variations in the aerosol properties at these three sites were similar. The Mt_WLG site is located in the northeast of the TP, which is different from the southern sites. The Muztagh_Ata is in the northwest of the TP and is the closest site to the Taklimakan Desert, which causes the high AOD there (a few observed data may be another reason). Looking at the monthly CE318_AOD and EAE values together, high CE318_AOD was often accompanied by low EAE at Lhasa, Mt_WLG and NAM_CO, indicating that these sites suffered from coarse aerosols such as dust (Huang et al., 2007; Liu et al., 2015; Zhang et al., 2001). However, the QOMS_CAS site showed high CE318_AOD and high EAE in April, which may be related to smoke aerosols transported from South Asia.

Table 2 shows the seasonal statistics of CE318_AOD and EAE. A distinct seasonal variation in CE318_AOD and EAE can be found over the TP sites. The CE318_AOD mean values in fall (SON) and winter (DJF) were lower at all sites except Muztagh. Muztagh_Ata showed high CE318_AOD in both observed seasons. Except for that in Muztagh, the maximum seasonal CE318_AOD was observed in spring (MAM) (Lhasa, NAM_CO and QOMS_CAS) or in summer (JJA) (Mt_WLG). The minimum seasonal EAE occurred in spring (Lhasa and Mt_WLG) or summer (NAM_CO and QOMS_CAS), while the maximum EAE values were mostly observed in fall (Lhasa and Mt_WLG) and winter (NAM_CO and QOMS_CAS). These indicated frequent dust events over the TP in the spring and summer period. Mt_WLG is situated on the dust transport path from the Taklimakan Desert, which causes the high CE318_AOD observed in spring and summer at this site.

The seasonal size distributions of the five sites in Fig. 3 also demonstrated that coarse-mode aerosol was dominant at the five TP sites in almost all seasons, which was different from those in the eastern pollution regions of China, such as the Yangtze River Delta, where fine-mode aerosol 

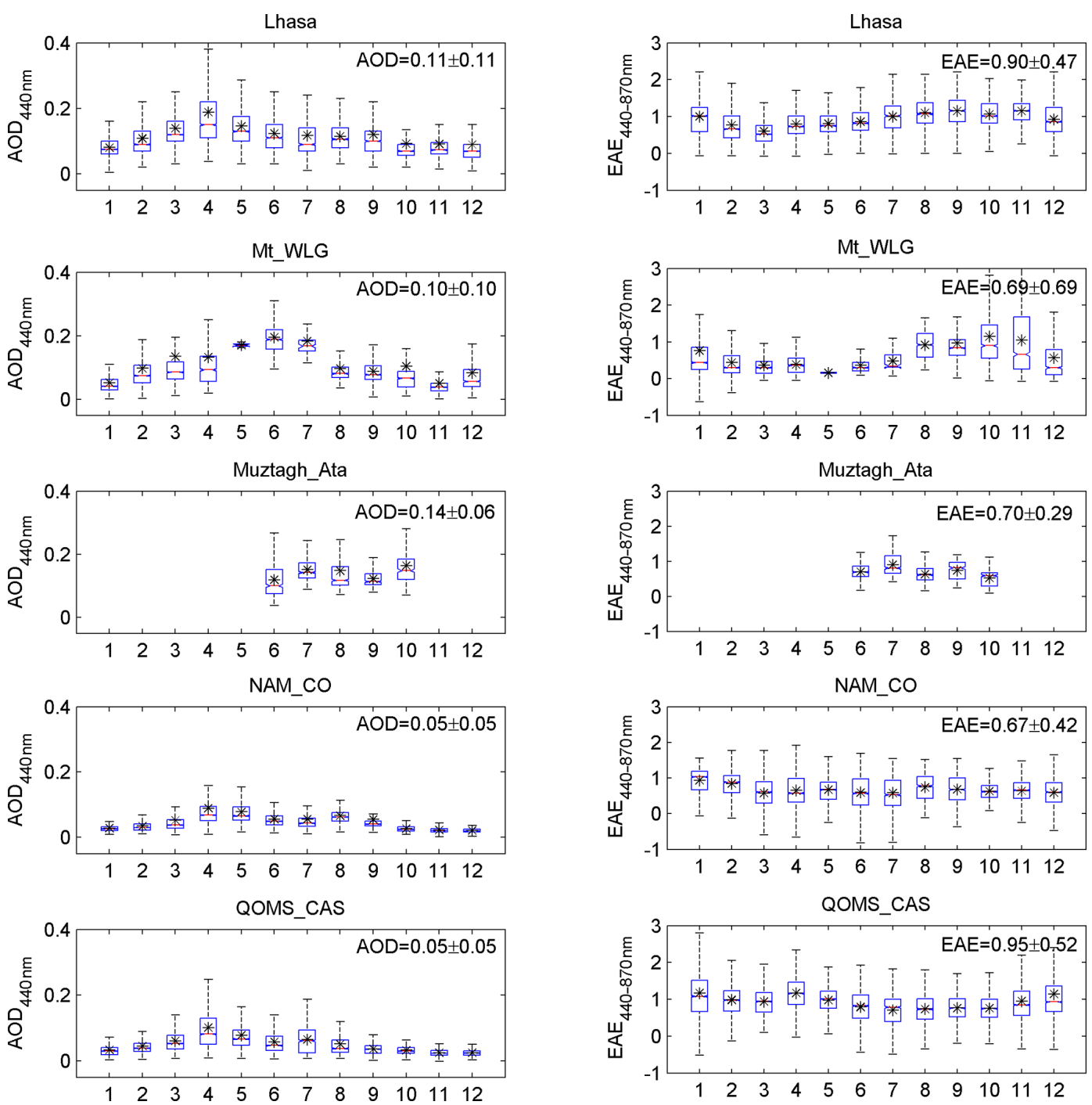

Figure 2. Box plots of the monthly aerosol optical depth (AOD) and extinction Ångström exponent (EAE) from CE318 at the five sites located on the Tibetan Plateau, i.e., Lhasa, Mt_WLG, Muztagh_Ata, NAM_CO and QOMS_CAS. In each box, the red line in the center is the median, and the lower and upper limits are the first and the third quartiles, respectively. The lines extending vertically from the box indicate the spread of the distribution with the length being 1.5 times the difference between the first and the third quartiles. The asterisk symbols indicate the geometric means in each month. The annual mean values and errors are also shown in each subgraph.

was dominant (Zhuang et al., 2018). This size distribution explained the relatively low annual averages of EAE at the five sites (all annual EAE in Fig. 2 are less than 1.0), compared to those at the inland urban and suburban sites in China (Xin et al., 2007), such as Beijing (1.19) (Fan et al., 2006), Nanjing (1.20) (Zhuang et al., 2017, 2018), Kunming (1.25) (Zhu et al., 2016) and Chengdu (1.09) (Che et al., 2015). In addition, spring was the season with a high volume concentration of coarse-mode aerosol. Among the five sites, the southernmost site, QOMS_CAS, showed the highest annual mean EAE, and the size distribution was distinctly bimodal, especially in spring. This was also because of the frequent biomass burning activity in India and Nepal, which can transport the fine aerosol to the QOMS_CAS site.
The annual averages of CE318_AOD (shown in Fig. 2) were $0.05-0.14$ over TP sites. These average values were lower than those in other regional background sites, such as Longfengshan (0.35) in northeast China (Wang et al., 2010), Xinglong (0.28) in the North China Plain (Zhu et al., 2014), Lin'an (0.89) in East China (Pan et al., 2010) and Dinghushan (0.91) in South China (Chen et al., 2014). The low aerosol loading over the five TP sites indicates excellent air quality over the TP region.

However, the aerosol loading at the TP sites presented interannual changes. The annual variations in CE318_AOD and EAE over the TP at the four sites, i.e., Lhasa, Mt_WLG, NAM_CO and QOMS_CAS, are shown in Fig. 4. The data for the CE318 observations at the Muztagh_Ata site are only 

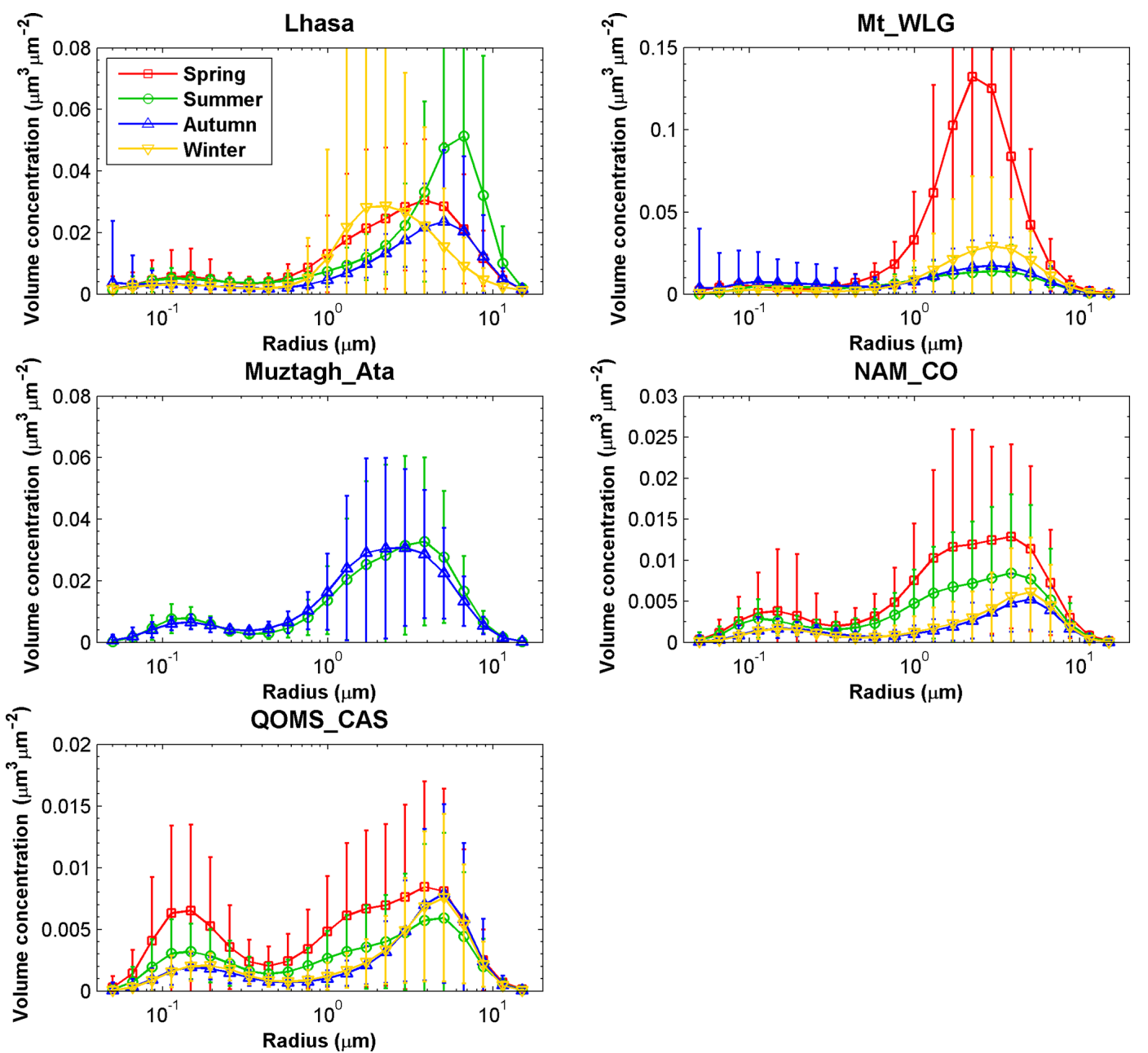

Figure 3. Seasonal variation in aerosol size distribution at the five sites located in the Tibetan Plateau.

available for 2010; thus, the annual variation at this site is not shown here. The annual CE318_AOD showed increasing trends of $0.001 \pm 0.003 \mathrm{yr}^{-1}$ at Lhasa, $0.013 \pm 0.003 \mathrm{yr}^{-1}$ at Mt_WLG and $0.002 \pm 0.002 \mathrm{yr}^{-1}$ at NAM_CO during the CE318 observation period. The Mt_WLG site showed the most obvious increase in CE318_AOD during 2009-2013. These results indicated an increase in aerosol loading at the three sites. The long-term annual variation of CE318_AOD at QOMS_CAS was very small $\left(0.000 \pm 0.002 \mathrm{yr}^{-1}\right)$, but there were still short-term annual variations (the values decreased from 2010 to 2013 and increased from 2013 to 2016). The annual trends of EAEs were more evident than the CE318_AOD at these four site. Most sites showed an increasing tendency in the average annual EAE except for the Mt_WLG site, which showed a large decreasing trend of $-0.318 \pm 0.081 \mathrm{yr}^{-1}$. This showed that the size of aerosol at the Mt_WLG site increased, while the size of the aerosol decreased in the other three sites. Looking at the CE318_AOD and EAE values together, the positive trend of CE318_AOD and the positive trend of EAE in the long-term variation at most sites over the TP indicated the addition of fine-mode aerosol which may be related to the anthropogenic impact or long-distance transport of polluted dust to the TP. However, in the short term, the increase in the average annual CE318_AOD was often associated with the decrease in EAE over the TP, which suggested the addition of coarse-mode aerosol during the CE318 observation period.

\subsection{Aerosol properties from MODIS}

Ground-based observations can offer accurate aerosol optical properties at point locations but lack spatial coverage. The MODIS aerosol product can provide the spatial variation in AOD over the TP. Thus, we evaluated the MODIS_AOD using the ground-based observation CE318_AOD at $550 \mathrm{~nm}$ over the TP sites. The CE318_AOD at $550 \mathrm{~nm}$ was interpolated from 440, 675, 870 and $1020 \mathrm{~nm}$ by using an established fitting method from Ångström (1929). The matchup method was that the CE318 data within $1 \mathrm{~h}$ of the MODIS overpass were compared with the MODIS data within a 

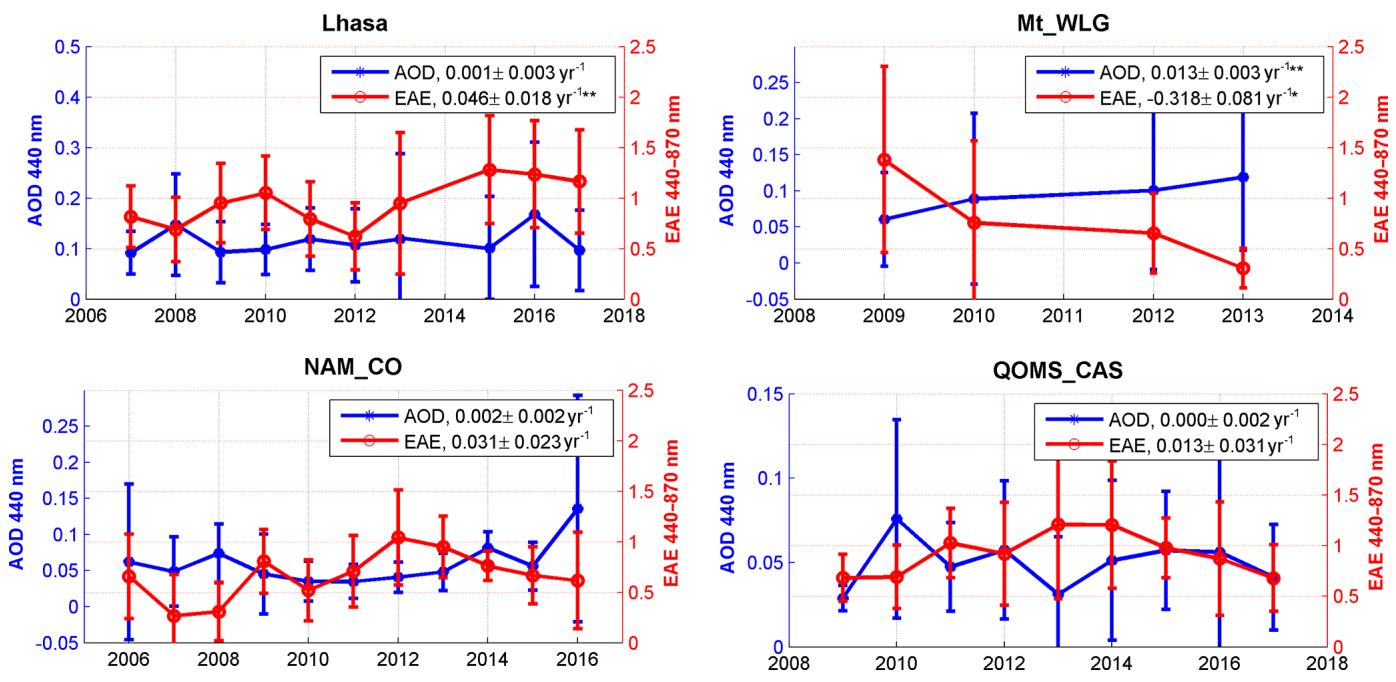

Figure 4. Annual averages of and trends in AOD and EAE from CE318 at four sites located in the Tibetan Plateau.

$25 \mathrm{~km}$ radius of the ground-based site. The minimum requirement for a matchup was at least 3 pixels from MODIS.

Figure 5 shows the results of MODIS_AOD compared to the collocated ground CE318 observations over the TP. There were 996 instantaneous matchups of Terra and Aqua MODIS during the CE318 instrument measurement period at the five TP sites. The MODIS_AOD overestimated the AOD at $550 \mathrm{~nm}$ with a positive mean bias of 0.02 and a RMSE of 0.11 . The RMSE value was lower than that of the North China Plain sites $(\sim 0.25)$ (Bilal et al., 2019). The slope and intercept of the best-fit equation between the MODIS_AOD and CE318_AOD at $550 \mathrm{~nm}$ were 0.46 and 0.06 , respectively, with a correlation coefficient $(R)$ of 0.54 . There were $67.8 \%$ of the compared AODs within the expected error envelope of $0.05+0.15 \mathrm{AOD}(\% \mathrm{EE})$. The $R$ value was lower than that in the global assessment statistics, while the $\% \mathrm{EE}$ was higher than that in the global evaluation (Bilal and Qiu, 2018). Overall, the results suggest that the MODIS_AOD product can be used to study the aerosol spatial variation over the TP region.

The spatial distribution of the annual MODIS_AOD is shown in Fig. 6. The MODIS_AOD agreed with the CE318_AOD at $550 \mathrm{~nm}$ at the five TP sites. The northwest area around the Taklimakan Desert and the northern part of the TP on the transport path of the Taklimakan Desert dust showed high MODIS_AOD $(>0.25)$ in recent decades. In addition, the southern edge showed slightly high MODIS_AOD (0.2-0.25) influenced by the aerosol transport from South Asia. There were some small areas with high MODIS_AOD $(\sim 0.2)$ in the center of the TP, and the southeast region showed low MODIS_AOD $(\sim 0.1)$, which may be attributed to the aerosol transport and surface features such as vegetation cover, since there are few inhabitants. The seasonal departure of MODIS_AOD (Fig. 7) showed that high positive MODIS_AOD departure often appeared in spring, especially for the northwest edge, northern area and

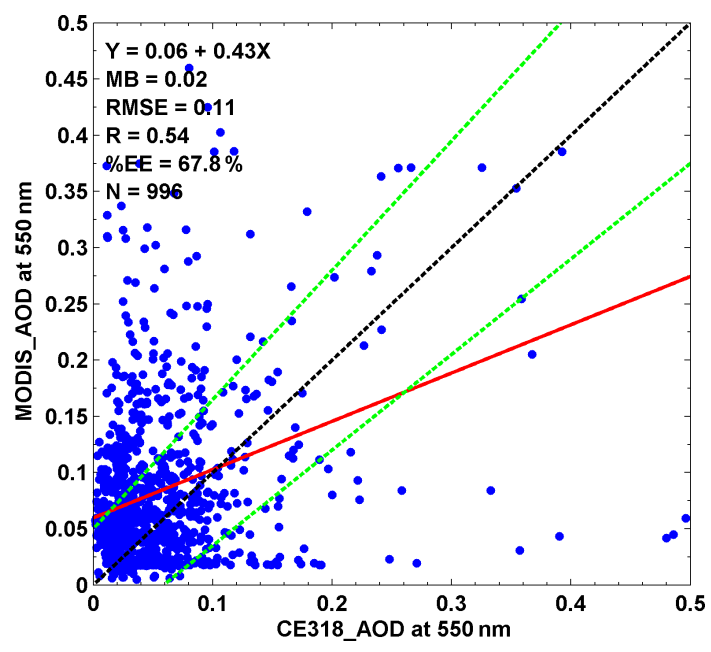

Figure 5. Comparisons of the $550 \mathrm{~nm}$ AOD measured by the CE318 instrument (CE318_AOD) over Tibetan Plateau stations with the MODIS retrieval Deep Blue and Dark Target combined AOD of $10 \mathrm{~km}$ spatial resolutions (MODIS_AOD). The statistical parameters in this figure include the number of matchup data $(N)$, the slope and intercept at the $y$ axis of linear regression (read line), the mean bias (MB), the root-mean-squared error (RMSE), the correlation coefficient $(R)$ and the percentage of data within the expected error $0.05+0.15$ AOD (\% EE) which is used as the MODIS AOD expected uncertainty over land (green lines).

southern edge of TP, which may be a result of aerosol transport from the frequent dust events in the Taklimakan Desert and the fire activities in South Asia in spring.

A linear regression analysis of the trends in annual MODIS_AOD over the TP from 2006 to 2017 was conducted using the least-squares method. The spatial distribution of the annual trends in MODIS_AOD during 2006-2017 is illustrated in Fig. 8. There were no statistically significant 


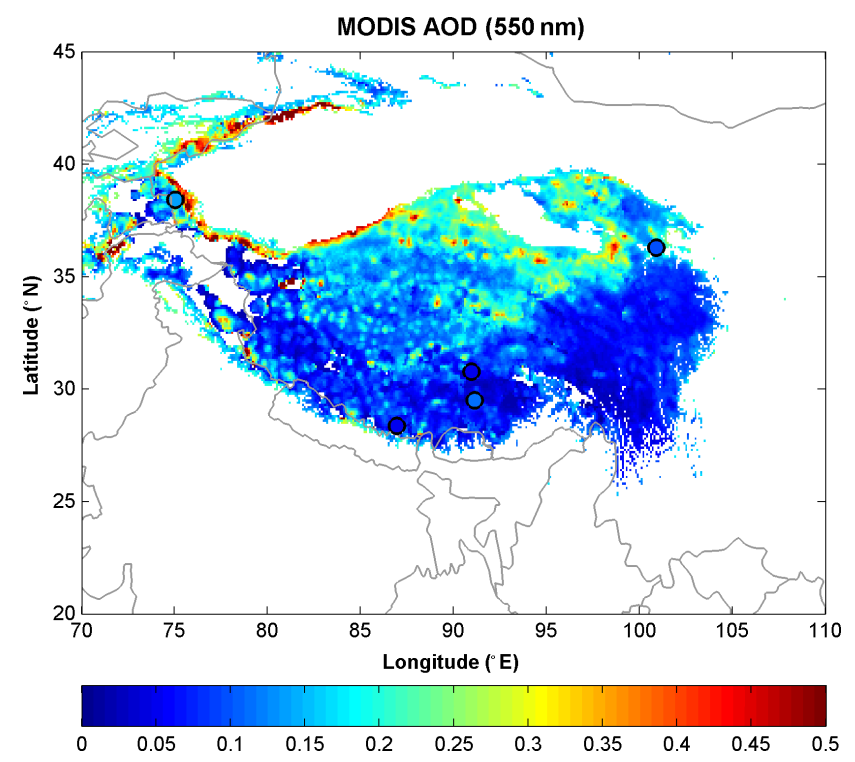

Figure 6. Spatial distribution of MODIS_AOD at $550 \mathrm{~nm}$ over the Tibetan Plateau (only the altitude $>3000 \mathrm{~m}$ ) during 2006-2017. The color-filled circles are the CE318 observation AOD averages at TP sites.

trends in most areas during 2006-2017. The MODIS_AOD showed negative trends in the northwest edge close to the Taklimakan Desert and to the east of the Qaidam Basin and slightly positive trends in most of the other areas. The areas where MODIS_AOD decreased were mainly located near the desert or on the transport path of the desert dust. This descending trend may be related to the significant reduction in dust emissions caused by the decline in wind speed in recent years (Yang et al., 2017b). The positive trend in most other areas may be due to the rapid increase in human activities, such as the expansion of tourism to the TP and biomass burning in South Asia.

The seasonal trends in MODIS_AOD at $550 \mathrm{~nm}$ over the TP during 2006-2017 are presented in Fig. 9. The spring showed the most obvious decline in MODIS_AOD $\left(\sim 0.02 \mathrm{yr}^{-1}\right)$ at the northern edges and northeast part of the TP during 2006-2017, which may also be related to the reduction in dust emissions as the trend in the annual MODIS_AOD (seen in Fig. 8). In summer, the positive trend in MODIS_AOD over the TP was relatively apparent, and most sporadic higher positive values of $\sim 0.01$ occurred in the central and southern part of the TP. Summer is the tourist season in the TP, and tourism has developed in past decades, which may be one of the reasons for the higher positive trend in summer in the TP. The positive trends in autumn and winter were relatively lower than those in summer, and the most positive trends were located at the northern TP. The reason for this phenomenon needs to be explored.

\section{Aerosol properties and potential sources during high aerosol loading}

The annual mean AOD in the TP was normally low due to the few human inhabitants and high altitude. However, some high CE318_AOD values larger than 0.4, which is normally regarded as high aerosol loading (Eck et al., 2010; Giles et al., 2012), were observed at the five sites in the TP by CE318. Thus, the CE318_AOD larger than 0.4 over TP can be considered the aerosol pollution. The frequencies of high aerosol loading (CE318_AOD > 0.4) during the CE318 measurements were $1.57 \%, 1.79 \%, 0.21 \%, 0.42 \%$ and $0.11 \%$ at the Lhasa, Mt_WLG, Muztagh_Ata, NAM_CO and QOMS_CAS sites, respectively. The aerosol properties and sources during high aerosol loading in the TP need to be studied.

Figure 10 shows the CE318_AOD with values larger than 0.4 versus EAE observed by CE318 at the five sites in the TP. Except for the Lhasa and Mt_WLG sites, almost all values of CE318_AOD were less than 1.0, which reflected the relatively clear environment over the TP. The EAE showed two centers at $\sim 0.1$ and $\sim 1.5$. The low EAE $(\sim 0.1)$ center was related to dust events, which can cause higher concentrations of coarse particles in the atmosphere. Besides, most values of the low EAE $(<0.5)$ area were less than 0.2 (only a few EAEs between 0.2 and 0.5 were observed at Lhasa and Mt_WLG), indicating that the puredust-type aerosols were more common than the polluteddust-type aerosols in the TP according to Eck et al. (2010). The high EAE center at $\sim 1.5$ indicated mainly small submicron radius particles, which can be attributed to anthropologic emissions. The values of EAE $>1.0$ at the NAM_CO and QOMS_CAS sites were generally higher than those at the Lhasa and Mt_WLG sites. According to past studies, the EAE of biomass burning aerosol is generally higher than the urban/industry aerosol (Giles et al., 2012; Eck et al., 2010), which may cause the higher EAE at NAM_CO and QOMS_CAS (more biomass burning aerosol) than at Lhasa and Mt_WLG (more urban/industry aerosol) for the high EAE area. On the other hand, the values in the middle range of 0.5-1.0 were rare, indicating a smaller mix of natural and human sources. The percentage of EAE bins to the number of CE318_AOD $>0.4$ was distinct (Table 3). The percentage of $\mathrm{EAE}<0.5$ was higher than that of EAE $>1.0$ at Lhasa, Mt_WLG and Muztagh_Ata, indicating more nature dust pollution than the anthropogenic pollution at these three sites. However, a greater number of high EAE values $(>1.0)$ were observed than EAE $<0.5$ values at the NAM_CO and QOMS_CAS sites, suggesting that anthropogenic pollution was more than natural dust pollution at these two sites.

Figure 11 shows the aerosol size distribution binned by CE318_AOD at the five sites in the TP. The volume concentration of coarse-mode particles increased more apparently than fine mode at Lhasa, Mt_WLG and Muztagh sites when the values of CE318_AOD increased. However, the size dis- 

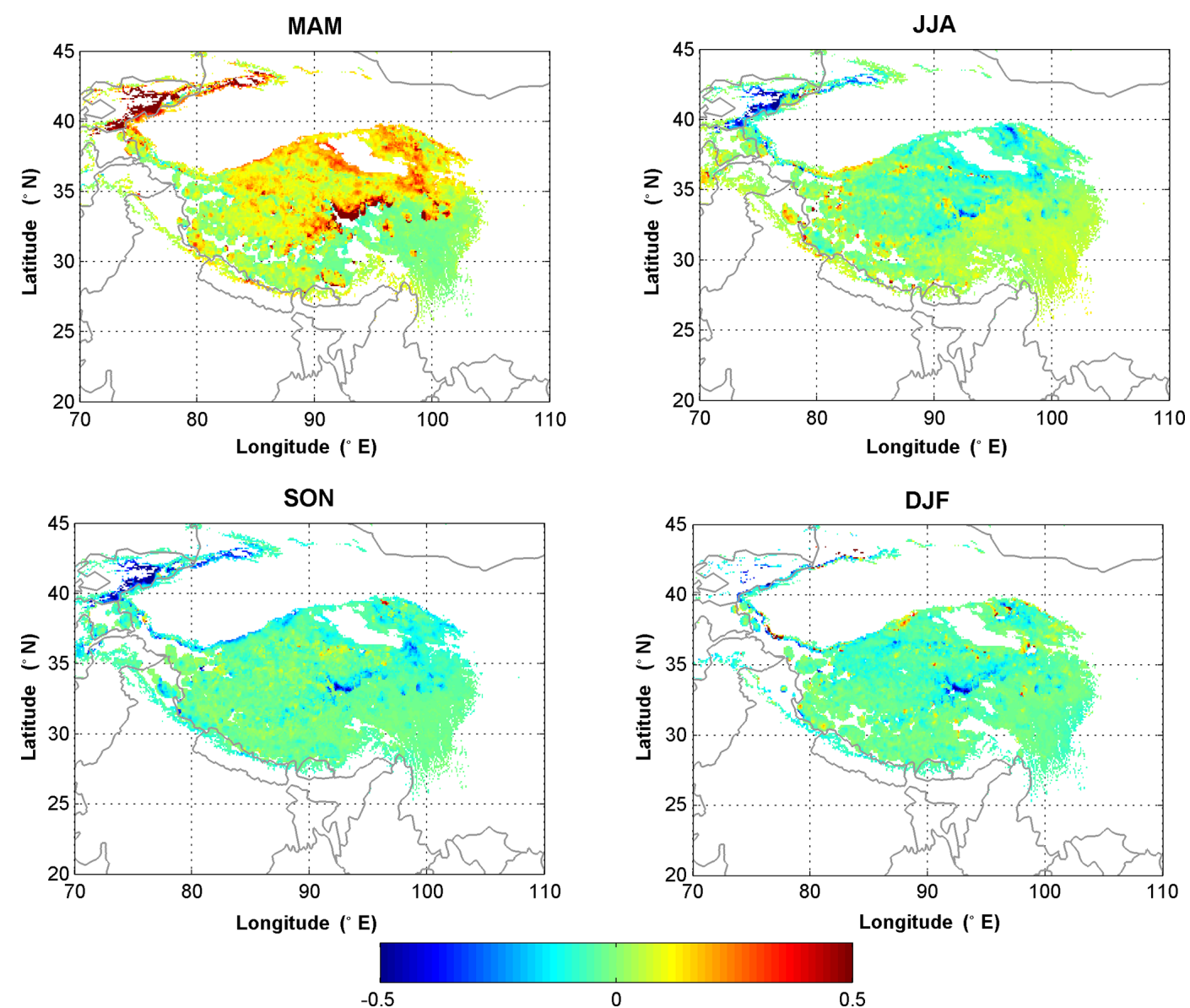

Figure 7. The seasonal departure of MODIS_AOD over the Tibetan Plateau (altitude $>3000 \mathrm{~m}$ ).

Table 3. The percentages of $\mathrm{EAE}<0.5,0.5-1.0$, and $>1.0$ for high AOD observations at the five sites.

\begin{tabular}{lrrrr}
\hline Site & $N$ of $\mathrm{AOD}>0.4$ & $\% \mathrm{EAE}<0.5 / N$ & $\% 0.5<\mathrm{EAE}<1.0 / N$ & $\% \mathrm{EAE}>1.0 / N$ \\
\hline Lhasa & 655 & 60.6 & 3.4 & 36.0 \\
Mt_WLG & 290 & 73.4 & 0 & 26.6 \\
Muztagh_Ata & 5 & 100 & 0 & 0 \\
NAM_CO & 140 & 27.9 & 2.8 & 69.3 \\
QOMS_CAS & 59 & 23.7 & 0 & 76.3 \\
\hline
\end{tabular}

tribution at NAM_CO and QOMS_CAS showed the dominant increase in fine-mode aerosol. These indicate the different aerosol pollution type in these five sites: dust dominant in Lhasa, Mt_WLG and Muztagh_Ata and fine-mode aerosol (mainly biomass burning aerosol) pollution dominant at NAM_CO and QOMS_CAS.

The dominant aerosol pollution type showed obvious distinctions among the five sites on the TP, so what was the distinct aerosol pollution source at each site? We used the HYSPLIT back-trajectory model and the MODIS_AOD on the day with aerosol pollution (CE318_AOD > 0.4) to show the aerosol source for the pollution day at each site. Figure 12 shows the $72 \mathrm{~h}$ back trajectories ending at the five sites
(10 m a.g.l.) in the TP overlaid with the mean MODIS_AOD on the aerosol pollution day which was observed by the ground-based CE318 (CE318_AOD > 0.4). The CE318 instruments observed 78, 20, 2, 15 and $14 \mathrm{~d}$ at Lhasa, Mt_WLG, Muztagh_Ata, NAM_CO and QOMS_CAS, respectively, with instantaneous CE318_AOD $>0.4$. The aerosol pollution days at Lhasa, Mt_WLG and Muztagh_Ata observed by CE318 often had low EAE (black lines). The airflows ending at the Lhasa site on the polluted days were mainly from the northwest and southwest. The MODIS_AOD around Lhasa in the area of the back trajectories with CE318 EAE $<0.5$ passing did not show significantly high values, especially in the Taklimakan Desert, 


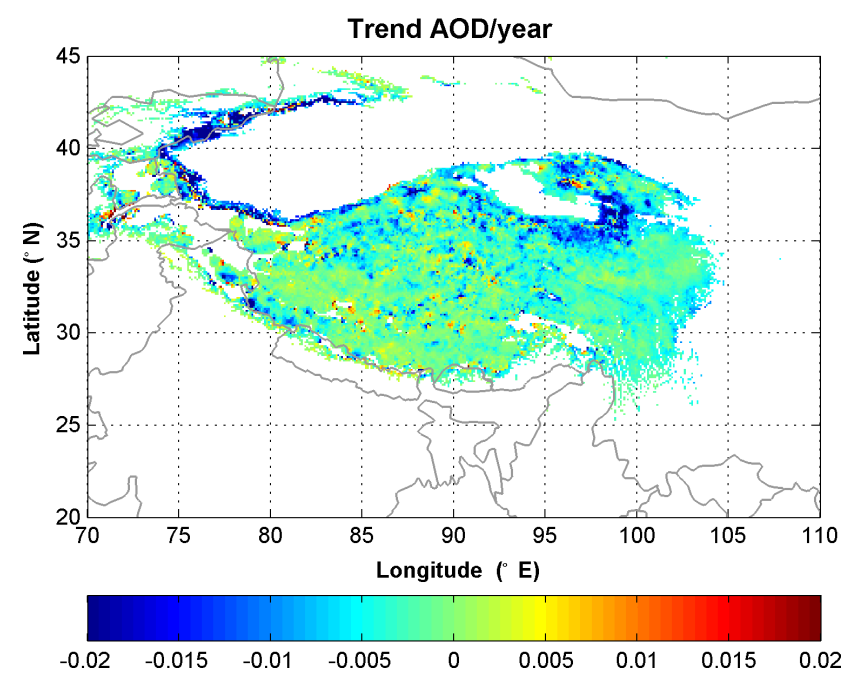

Figure 8. Trend in the MODIS_AOD at $550 \mathrm{~nm}$ during 2006-2017.

which indicated that the dust pollution at Lhasa was mainly from local or surrounding dust events rather than transport from the Taklimakan Desert. The Mt_WLG showed that the air mass on the pollution days comes from the west and east and the path of back trajectories had high MODIS_AOD. The high values of MODIS_AOD showed two transport paths of dust aerosol to Mt_WLG: one was through the Qaidam Basin and the other was through the northeast edge of the TP. The two polluted days observed by CE318 at the Muztagh_Ata showed the easterly airflows originating from the Taklimakan Desert. The direction of the back trajectories of EAE $<0.5$ that ended at NAM_CO was similar to Lhasa, while the southerly air flows with high EAE (red trajectories) originated from Nepal, where frequent biomass burning happened and caused the high MODIS_AOD values. The trajectories ending at QOMS_CAS and the high MODIS_AOD of the path revealed the transport of finer aerosol from South Asia to this site.

\section{Case study of long-range transport to the TP}

The long-range transport of aerosol can cause the aerosol pollution and affect the long-term variation in aerosol over the TP. In addition, the dominant aerosol type may change at the TP sites during a case of aerosol transport. Thus, a specific case of aerosol pollution during 27 April-3 May 2016 was analyzed further. This case was selected based on the observations from the CE318 instruments. During 28 April-1 May, the instantaneous CE318_AOD at the Lhasa, NAM_CO and QOMS_CAS sites showed the values larger than 0.4, which reached up to more than 3 times the mean values of CE318_AOD of each site (0.11 at Lhasa, 0.05 at NAM_CO and QOMS_CAS). This was indicative of aerosol pollution at the three sites. Then, how about the aerosol prop- erties of this period and where did the polluted aerosol originate?

Figure 13 shows the daily CE318_AOD and EAE during 27 April-3 May at the three sites. The mean values of CE318_AOD were $0.45,0.38$ and 0.23 at Lhasa, NAM_CO and QOMS_CAS, respectively. These even reached 4 times the annual mean CE318_AOD at each site. The mean EAEs were 0.98, 1.22 and 1.44 at Lhasa, NAM_CO and QOMS_CAS, respectively, which were higher than the annual averages and suggested the arrival of fine aerosols. There were CE318_AOD peaks at the three sites during 27 April-3 May. Lhasa showed an increase in CE318_AOD from 0.30 on 27 April to 0.51 on 28 April and maintained a high CE318_AOD to a value of 0.54 on 1 May, after which it decreased to 0.34 on 2 May. NAM_CO also showed an increase in CE318_AOD during the first $2 \mathrm{~d}$ of the period but decreased after 29 April. QOMS_CAM showed a slight increase in CE318_AOD from 27 April to 30 April, which was later than those of the other two sites. Combining the EAE on these days, fine-mode aerosol was brought to Lhasa and NAM_CO during 27-29 April, and then coarse aerosol began to occur on 30 April and even became the dominant aerosol in the following several days. The fine aerosol at the QOMS_CAM site was maintained for an additional day after those at the two sites, and then the coarse aerosol increased.

The GEOS-Chem model simulation also supported the above results. Figure 14 shows the comparison between the Model_AOD $\left(0.5^{\circ} \times 0.667^{\circ}\right)$ and CE318_AOD at $550 \mathrm{~nm}$ and the ratios of the model-simulated aerosol types (dust, both organic carbon (OC) and black carbon (BC) aerosol) to the total Model_AOD during this case period at the three sites. The evaluation results showed that the model underestimated the daily AOD at the three sites during this period, with negative mean biases from -0.28 to -0.08 . However, the Model_AOD was relatively highly correlated with the CE318_AOD at $550 \mathrm{~nm}$, with the $R$ values of 0.61 at Lhasa, 0.89 at NAM_CO and 0.86 at QOMS_CAS. These $R$ values were higher than the model evaluation in South China and the Indo-China Plain $(\sim 0.5)$ (Zhu et al., 2017). Thus, the variation trend from Model_AOD agreed well with that measured by the CE318 instruments during these days. During the first $4 \mathrm{~d}$ of the case period (27 April to 30 April), the ratios of different aerosols to the total Model_AOD showed that the sums of $\mathrm{OC}$ and $\mathrm{BC}$ aerosols were higher than those of dust aerosol at all three sites. Besides, the sums of $\mathrm{OC}$ and $\mathrm{BC}$ at Lhasa and QOMS_CAS were higher than that of NAM_CO. These indicated that the smoke aerosol affected the three sites more severely than dust during the first $4 \mathrm{~d}$, and Lhasa and QOMS_CAS sites were nearer to smoke sources than NAM_CO. After 30 April, the sum of BC and OC decreased while dust increased, and the increase in dust at the three sites was NAM_CO > Lhasa > QOMS_CAS. Therefore, the major aerosol source was changed and the NAM_CO site was closer to the dust source after 30 April. This phenomenon had continued until 2 May at NAM_CO and Lhasa and until 

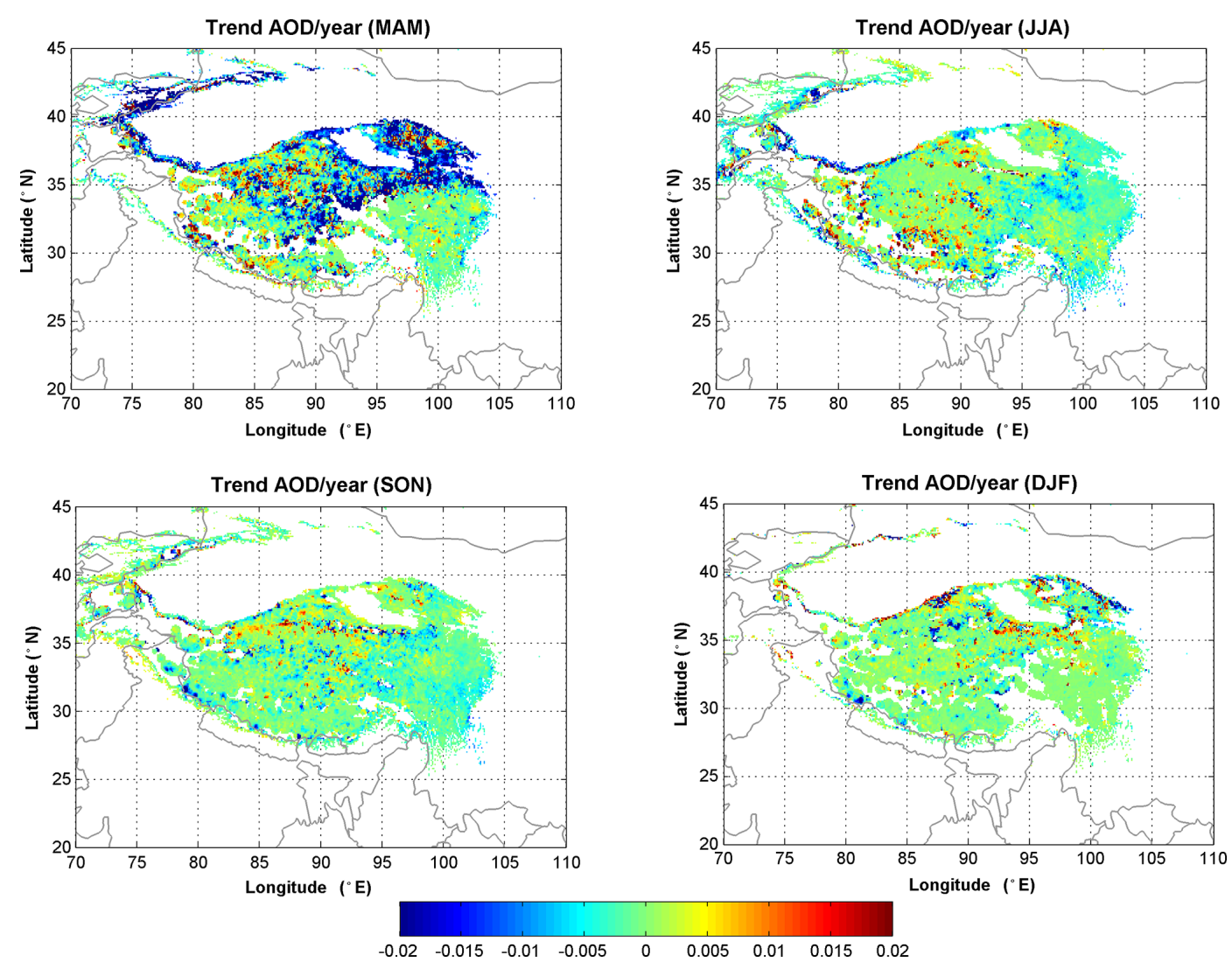

Figure 9. Trends in the MODIS_AOD at $550 \mathrm{~nm}$ during 2006-2017 in each season.

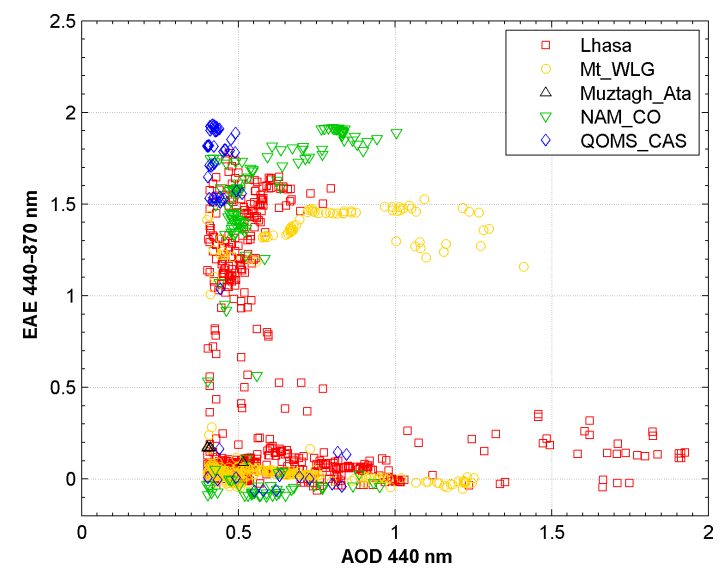

Figure 10. AOD vs. EAE (only CE318_AOD at $440 \mathrm{~nm}>0.4$ was considered) observed by CE318 at the five sites on the Tibetan Plateau.

1 May at QOMS_CAS. In the last 1 or $2 \mathrm{~d}$, the dust decreased while the $\mathrm{BC}$ and $\mathrm{OC}$ obviously increased, which could cause the mixture of different aerosols.

Then, how was the spatial aerosol loading around the TP and the vertical feature of aerosol transported to the TP? Figure 15 shows the MODIS_AOD and $72 \mathrm{~h}$ back trajectories at Lhasa (the first row); the CALIOP-derived vertical profile of total attenuated backscatter at $532 \mathrm{~nm}$ (the second row); and the vertical feature mask of aerosol (the third row) on 28 April, 1 May and 3 May during the case study period. The MODIS_AOD showed high values in the south (South Asia) and north (Taklimakan Desert) on the $3 \mathrm{~d}$. The high values in South Asia were caused by anthropogenic aerosols (such as biomass burning) or dust polluted by anthropogenic aerosols, while the high MODIS_AOD in the Taklimakan Desert resulted from dust. The values and areas of the high MODIS_AOD in South Asia and the Taklimakan Desert on 1 and 3 May were higher and larger than those on 28 April. The back trajectories ending at Lhasa on the $3 \mathrm{~d}$ were different. On 28 April, the air flows originated from the southwest (South Asia region). However, the air masses on 1 and 3 May were from the northwest (Taklimakan Desert).

The CALIPSO ground tracks across the TP and through South Asia and the Taklimakan Desert were chosen to show the aerosol transport to the TP sites. On 28 April, the Level 1 attenuated backscatter at $532 \mathrm{~nm}$ derived from CALIOP (the second row) showed apparent aerosol layers in the southern area (Bhutan and northeast India), and this aerosol layer even extended to an altitude of $\sim 10 \mathrm{~km}$ over the TP along the southern slope of the TP. On 1 May, the CALIOP attenuated backscatter not only showed the deep aerosol layers south 

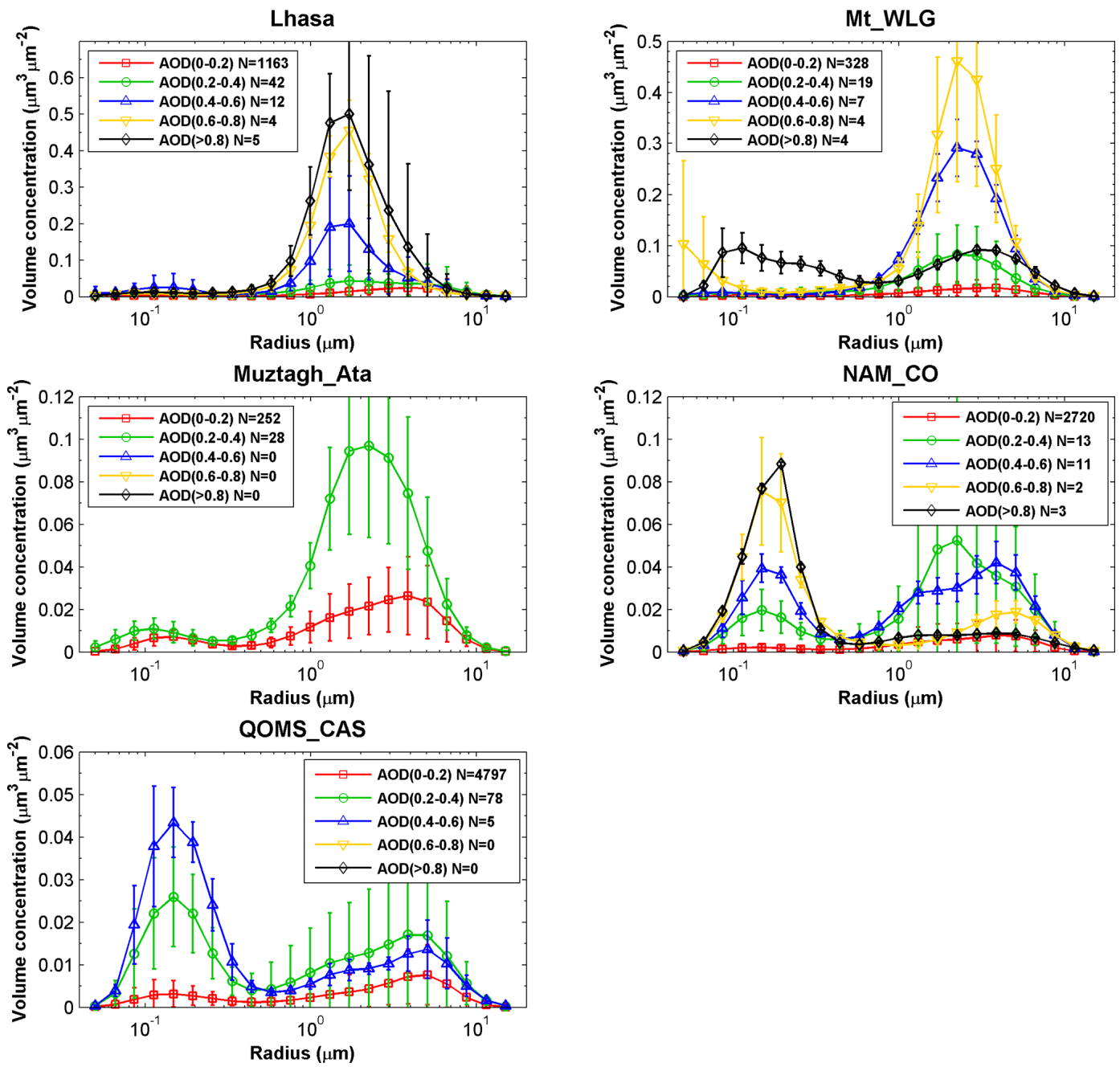

Figure 11. Aerosol size distribution binned by CE318_AOD at the five sites on the Tibetan Plateau.

of the TP but also showed stronger aerosol layers north of the TP (Taklimakan Desert area). Besides, the north aerosol layers also climbed into the air over the TP but not as high as the southern aerosol layer. On 3 May, there were also aerosol layers in the south and north of the TP that were both transported to above the TP, but the aerosol loading over the TP was lower than that on 28 April and 1 May (the values of attenuated backscatter on 3 May were lower), which corresponded to the lower CE318_AOD on this day than those on 28 April and 1 May at the three TP sites (Fig. 13).

The vertical feature mask of the aerosol from CALIOP (the third row) showed the aerosol types on the $3 \mathrm{~d}$. On 28 April, the aerosol layer in the north $\left(\sim 35^{\circ} \mathrm{N}\right)$ and above the TP was mainly the smoke aerosol and was even near to $10 \mathrm{~km}$. The back trajectories ending at Lhasa also showed that the southern airflow brought the smoke aerosol and polluted dust from South Asia to the center of the TP. On 1 May, the aerosol layer on the southern slope of the TP was also smoke aerosol and polluted dust, while the aerosol layers in the northern TP and above the TP were almost all dust aerosol, which could be explained by the northwest airflows carrying the dust aerosol from the Taklimakan Desert. These may be the result of the lower EAE values at Lhasa and NAM_CO than that at QOMS_CAM (Fig. 13). On 3 May, the aerosol type above the central TP and the southern TP was occupied by polluted dust aerosol, and the EAE at NAM_CO and QOMS_CAM also showed a slight increase on 3 May. These results agree with the aerosol simulation from GEOSChem. Jia et al. (2015) has shown that the dust from India polluted by anthropogenic aerosols can be transported to the TP, but the back trajectories on 1 and 3 May illustrated that the airflows that ended at Lhasa were from the north or northwest rather than the south, indicating that the polluted dust over the TP on 3 May was more likely the mixing result of dust and smoke aerosol. In addition, the lengths of the back trajectories (especially the back trajectories at $10 \mathrm{~m}$ and $500 \mathrm{~m}$ a.g.l.) on 1 May showed that the airflows moved slowly, which allowed the possibility of aerosol mixture over 

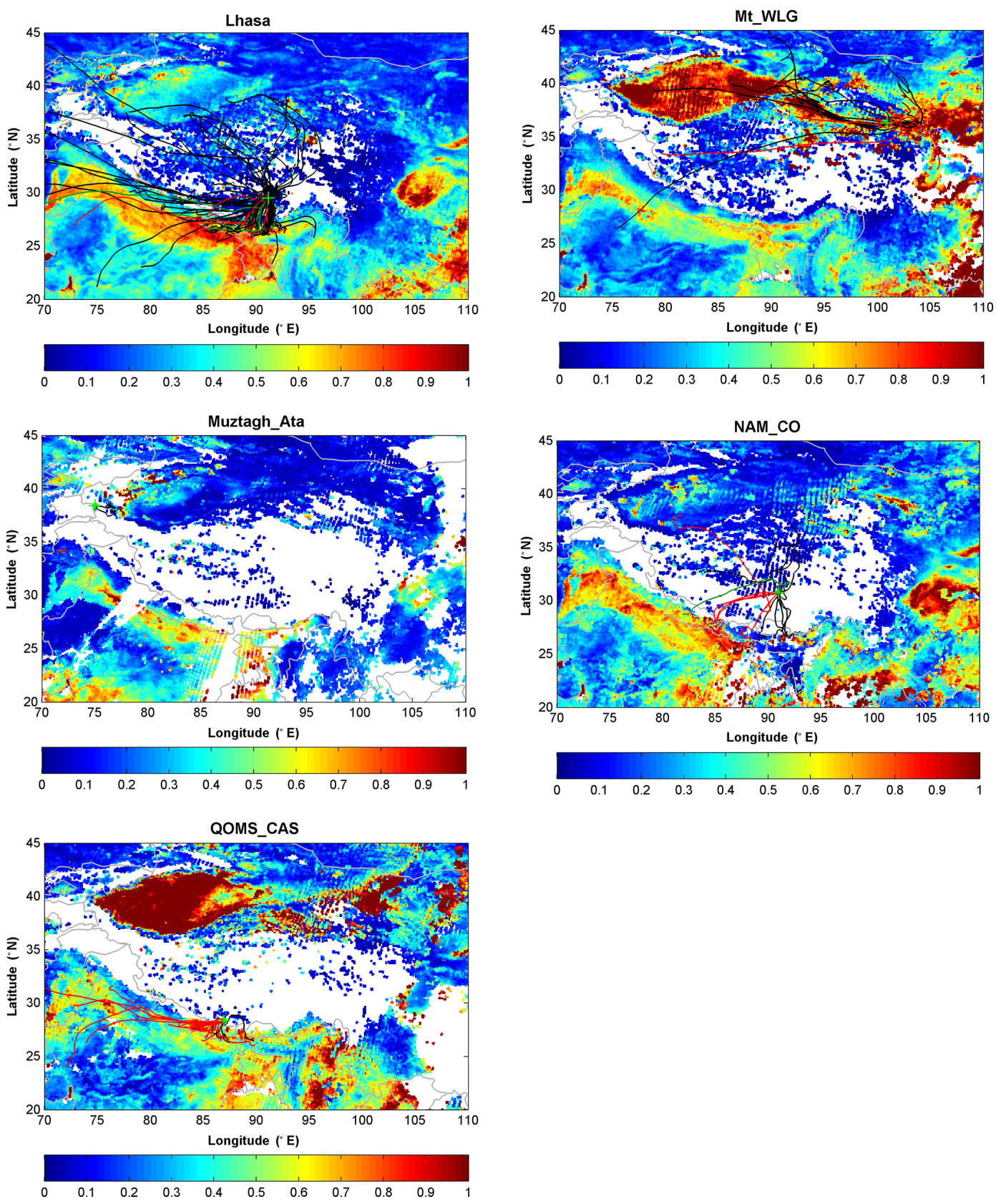

Figure 12. The back trajectories ending at the five sites (10 m a.g.1.) on the Tibetan Plateau overlaid with the mean MODIS_AOD at 550 nm on the high aerosol loading day observed by ground-based CE318 (CE318_AOD > 0.4). Red stands for EAE $>1.0$, black for EAE < 0.5, and green for EAE within 0.5-1.0.

the TP. The observations and model simulations illustrated the following scene: first, the smoke aerosol in South Asia was lifted up to $10 \mathrm{~km}$, contaminating the TP sites, and transported to the center of the TP; then, the dust from the Taklimakan Desert could climb the north slope of the TP and be transported to the TP; finally, the dust and smoke aerosol over the TP were mixed. This case of aerosol pollution shows that the anthropogenic aerosols (mainly smoke) in South Asia and dust in the Taklimakan Desert could be transported to the center of the TP and they both can even cause mixed aerosol pollution above the TP. The past case studies of aerosol transport to the TP are mostly individual dust or smoke aerosol, while this case of aerosol pollution over the TP showed the mixing pollution during the last $2 \mathrm{~d}$ of the case period. 

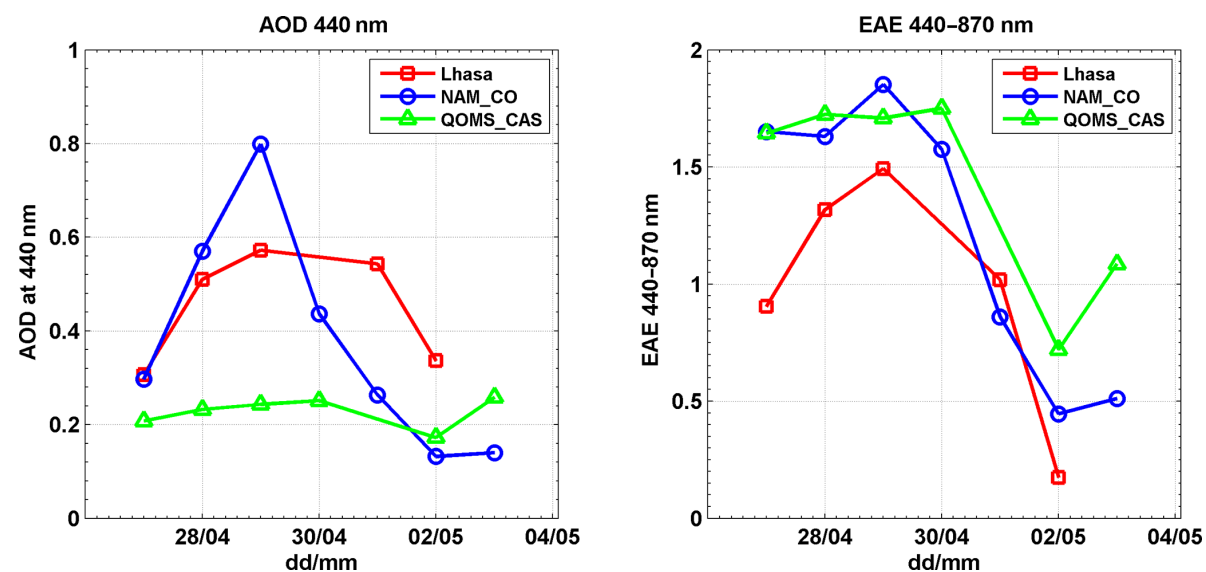

Figure 13. CE318-observed daily AOD and EAE during 27 April-3 May 2016 at Lhasa, NAM_CO and QOMS_CAS.
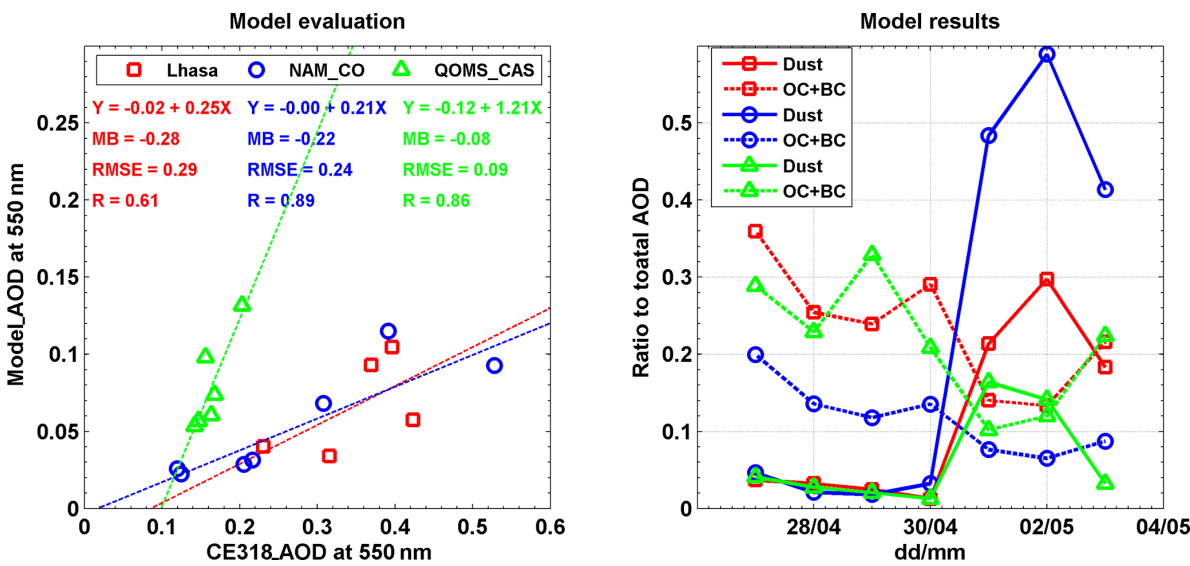

Figure 14. The model evaluation of the GEOS-Chem model simulated the daily average AOD (Model_AOD) by using the CE318-observed daily AOD (CE318_AOD) at $550 \mathrm{~nm}$ and the model results of the ratios of dust or organic carbon (OC) and black carbon (BC) aerosol to the total AOD during 27 April-3 May 2016 at Lhasa, NAM_CO and QOMS_CAS. The statistical parameters used in the modal evaluation are the same as those in Fig. 5.

\section{Conclusion}

The long-term spatiotemporal variations in the aerosol optical properties and the impacts of the long-range aerosol transport over the TP were analyzed by using a combination of ground-based and satellite remote-sensing aerosol products as well as model simulations. The major conclusions are drawn as follows:

1. The annual CE318_AOD at most TP sites showed increasing trends $\left(0-0.013 \mathrm{yr}^{-1}\right)$ during the past decade. Increasing tendencies in the annual averaged EAE were also found at most TP sites. Spatially, the MODIS_AOD showed negative trends in the northwest edge close to the Taklimakan Desert and the east of Qaidam Basin and slightly positive trends in most of the other areas of the TP.

2. Different aerosol types and sources contributed to the high aerosol loading at the five sites: dust was domi- nant in Lhasa, Mt_WLG and Muztagh with sources in the Taklimakan Desert, but fine-aerosol pollution was dominant at NAM_CO and QOMS_CAS with transport from South Asia.

3. A case of smoke followed by dust pollution at Lhasa, NAM_CO and QOMS_CAS during 28 April3 May 2016 showed that the smoke aerosol in South Asia was first uplifted to $10 \mathrm{~km}$ and transported to the center of TP. Then, the dust from the Taklimakan Desert could climb the northern slope of the TP and be transported to the TP, allowing the dust and smoke aerosol over the TP to mix.

There are some limitations to this study. First, ground-based remote-sensing and MODIS_AOD products may have had missing data due to cloud interference. Second, only half of a year of observations at the Muztagh_Ata station may not be sufficient to fully reveal pollution days in the northwest TP region, which could have affected the statistics to 

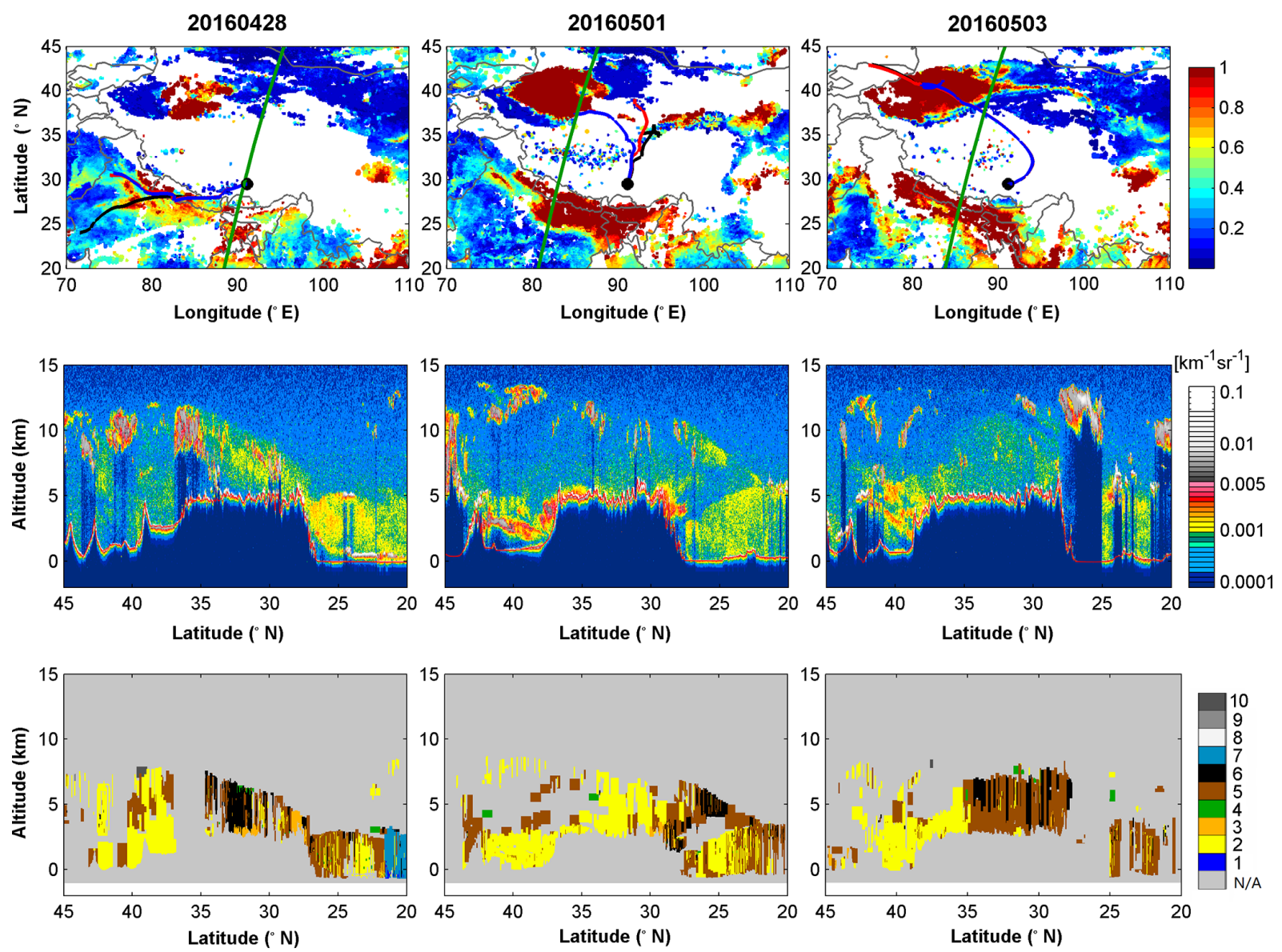

$\mathrm{N} / \mathrm{A}=$ not applicable $1=$ marine $2=$ dust $3=$ polluted continental/smoke $4=$ clean continental $5=$ polluted dust $6=$ elevated smoke

$7=$ dusty marine $8=\mathrm{PSC}$ aerosol $9=$ volcanic ash $10=$ sulfate/other

Figure 15. The MODIS_AOD at $550 \mathrm{~nm}$ and $72 \mathrm{~h}$ back trajectories ending at Lhasa at three heights above the ground level (10 $\mathrm{m}$ in black, $500 \mathrm{~m}$ in red and $1000 \mathrm{~m}$ in blue lines) (the first row); the CALIOP-derived vertical profile of total attenuated backscatter at $532 \mathrm{~nm}$ (the second row); and the vertical feature mask of aerosol on 28 April, 1 May and 3 May 2016 (the third row). The green lines in the panels of the first row stand for the CALIOP ground tracks.

some extent. More long-term in situ observations are needed in the TP. However, due to the remoteness and challenging weather conditions over the plateau, maintaining long-term in situ observation stations over the TP is very difficult. The numerical model simulation is more practically feasible to study the aerosol properties over the TP, but the model accuracy is far from ideal over the TP. Thus, long-term numerical model simulation coupled with satellite observations and intensive short-term field campaigns should be used to analyze the aerosol properties over the TP in the future.

Data availability. The data for the four sites (Mt_WLG, Muztagh_Ata, NAM_CO and QOMS_CAS) are available from the AERONET website (https://aeronet.gsfc.nasa.gov/, last access: 30 November 2019). The dataset of Lhasa used in the study can be requested by contacting the corresponding author. The MODIS aerosol products are available from http://ladsweb.nascom.nasa.gov (last access: 30 November 2019). The HYSPLIT model and meteo- rological fields' data can be from https://www.arl.noaa.gov/hysplit/ (last access: 30 November 2019). The CALIPSO data are from https://eosweb.larc.nasa.gov (last access: 30 November 2019). The GEOS-Chem model code and share data can be obtained from http://wiki.seas.harvard.edu/geos-chem (last access: 30 November 2019).

Author contributions. All authors helped to shape the ideas and review this paper. JZ, XX and HC designed and wrote the manuscript; JZ, XX, HC and JW helped to analyze the data; HC, XZ, SK and ZC carried out the sun photometer observations; and JW, ZC, SK, $\mathrm{TZ}, \mathrm{XY}$ and $\mathrm{YZ}$ provided constructive comments on this study.

Competing interests. The authors declare that they have no conflict of interest. 
Special issue statement. This article is part of the special issue "Study of ozone, aerosols and radiation over the Tibetan Plateau (SOAR-TP) (ACP/AMT inter-journal SI)". It is not associated with a conference.

Acknowledgements. This research was supported by the National Science Fund for Distinguished Young Scholars (41825011); the National Key R \& D Program Pilot Projects of China (2016YFA0601901 and 2016YFC0203304); the National Natural Science Foundation of China (41761144056, 41975161); the Strategic Priority Research Program of Chinese Academy of Sciences (XDA20040500); the Natural Science Foundation of Jiangsu Province (BK20170943); the Open fund by the Key Laboratory for Middle Atmosphere and Global Environment Observation (LAGEO), Institute of Atmospheric Physics (LAGEO2018-01); and the Key Laboratory of Atmospheric Chemistry, China Meteorological Administration (LAC/CMA; 2018B02). We would like to thank the anonymous reviewers for their helpful comments that improved our paper.

Financial support. This research was supported by the National Science Fund for Distinguished Young Scholars (grant no. 41825011); the National Key R \& D Program Pilot Projects of China (grant nos. 2016YFA0601901 and 2016YFC0203304); the National Natural Science Foundation of China (grant nos. 41761144056 and 41975161); the Strategic Priority Research Program of Chinese Academy of Sciences (grant no. XDA20040500); the Natural Science Foundation of Jiangsu Province (grant no. BK20170943); the Open fund by the Key Laboratory for Middle Atmosphere and Global Environment Observation (LAGEO), Institute of Atmospheric Physics (grant no. LAGEO-2018-01); and the Key Laboratory of Atmospheric Chemistry, China Meteorological Administration (LAC/CMA; grant no. 2018B02).

Review statement. This paper was edited by Jianping Huang and reviewed by two anonymous referees.

\section{References}

Ångström, A.: On the atmospheric transmission of Sun radiation and on dust in the air, Geograf. Ann., 11, 156-166, https://doi.org/10.1080/20014422.1929.11880498, 1929.

Bey, I., Jacob, D. J., Yantosca, R. M., Logan, J. A., Field, B. D., Fiore, A. M., Li, Q., Liu, H. Y., Mickley, L. J., and Schultz, M. G.: Global modeling of tropospheric chemistry with assimilated meteorology: Model description and evaluation, J. Geophys. Res.-Atmos., 106, 23073-23095, https://doi.org/10.1029/2001jd000807, 2001.

Bilal, M. and Qiu, Z.: Evaluation of Modis C6 Combined Aerosol Product at Global Scale, in: IGARSS 2018-2018 IEEE International Geoscience and Remote Sensing Symposium, July 2018, Valencia, Spain, 9126-9129, 2018.

Bilal, M., Nazeer, M., Qiu, Z., Ding, X., and Wei, J.: Global Validation of MODIS C6 and C6.1 Merged Aerosol Products over Diverse Vegetated Surfaces, Remote Sens.-Basel, 10, 475, https://doi.org/10.3390/rs10030475, 2018.

Bilal, M., Nazeer, M., Nichol, J., Qiu, Z., Wang, L., Bleiweiss, M. P., Shen, X., Campbell, J. R., and Lolli, S.: Evaluation of Terra-MODIS C6 and C6.1 Aerosol Products against Beijing, XiangHe, and Xinglong AERONET Sites in China during 2004-2014, Remote Sens.-Basel, 11, 486, https://doi.org/10.3390/rs11050486, 2019.

Che, H., Zhang, X. Y., Xia, X., Goloub, P., Holben, B., Zhao, H., Wang, Y., Zhang, X. C., Wang, H., Blarel, L., Damiri, B., Zhang, R., Deng, X., Ma, Y., Wang, T., Geng, F., Qi, B., Zhu, J., Yu, J., Chen, Q., and Shi, G.: Ground-based aerosol climatology of China: aerosol optical depths from the China Aerosol Remote Sensing Network (CARSNET) 2002-2013, Atmos. Chem. Phys., 15, 7619-7652, https://doi.org/10.5194/acp15-7619-2015, 2015.

Che, H. Z., Wang, Y. Q., and Sun, J. Y.: Aerosol optical properties at Mt. Waliguan Observatory, China, Atmos. Environ., 45, 60046009, https://doi.org/10.1016/j.atmosenv.2011.07.050, 2011.

Chen, J., Xin, J., An, J., Wang, Y., Liu, Z., Chao, N., and Meng, Z.: Observation of aerosol optical properties and particulate pollution at background station in the Pearl River Delta region, Atmos. Res., 143, 216-227, https://doi.org/10.1016/j.atmosres.2014.02.011, 2014.

Cong, Z., Kang, S., Liu, X., and Wang, G.: Elemental composition of aerosol in the Nam Co region, Tibetan Plateau, during summer monsoon season, Atmos. Environ., 41, 1180-1187, https://doi.org/10.1016/j.atmosenv.2006.09.046, 2007.

Cong, Z., Kang, S., Smirnov, A., and Holben, B.: Aerosol optical properties at Nam Co, a remote site in central Tibetan Plateau, Atmos. Res., 92, 42-48, https://doi.org/10.1016/j.atmosres.2008.08.005, 2009.

Draxler, R. R. and Hess, G. D.: An overview of the HYSPLIT4 Modelling system for trajectories, dispersion and deposition, Aust. Meteorol. Mag., 47, 295-308, 1998.

Du, W., Sun, Y. L., Xu, Y. S., Jiang, Q., Wang, Q. Q., Yang, W., Wang, F., Bai, Z. P., Zhao, X. D., and Yang, Y. C.: Chemical characterization of submicron aerosol and particle growth events at a national background site (3295 ma.s.l.) on the Tibetan Plateau, Atmos. Chem. Phys., 15, 10811-10824, https://doi.org/10.5194/acp-15-10811-2015, 2015.

Dubovik, O. and King, M. D.: A flexible inversion algorithm for retrieval of aerosol optical properties from Sun and sky radiance measurements, J. Geophys. Res.-Atmos., 105, 20673-20696, https://doi.org/10.1029/2000jd900282, 2000.

Dubovik, O., Holben, B., Eck, T. F., Smirnov, A., Kaufman, Y. J., King, M. D., Tanré, D., and Slutsker, I.: Variability of Absorption and Optical Properties of Key Aerosol Types Observed in Worldwide Locations, J. Atmos. Sci., 59, 590-608, https://doi.org/10.1175/15200469(2002)059<0590:voaaop>2.0.co;2, 2002.

Dubovik, O., Sinyuk, A., Lapyonok, T., Holben, B. N., Mishchenko, M., Yang, P., Eck, T. F., Volten, H., Munoz, O., Veihelmann, B., van der Zande, W. J., Leon, J. F., Sorokin, M., and Slutsker, I.: Application of spheroid models to account for aerosol particle nonsphericity in remote sensing of desert dust, J. Geophys. Res.-Atmos., 111, 11201-11234, https://doi.org/10.1029/2005jd006619, 2006. 
Eck, T. F., Holben, B. N., Reid, J. S., Dubovik, O., Smirnov, A., O'Neill, N. T., Slutsker, I., and Kinne, S.: wavelength dependence of the optical depth of biomass burning, urban, and desert dust aerosols, J. Geophys. Res., 104, 31333-331349, https://doi.org/10.1029/1999JD900923, 1999.

Eck, T. F., Holben, B. N., Sinyuk, A., Pinker, R. T., Goloub, P., Chen, H., Chatenet, B., Li, Z., Singh, R. P., Tripathi, S. N., Reid, J. S., Giles, D. M., Dubovik, O., O’Neill, N. T., Smirnov, A., Wang, P., and Xia, X.: Climatological aspects of the optical properties of fine/coarse mode aerosol mixtures, J. Geophys. Res.Atmos., 115, D19205, https://doi.org/10.1029/2010jd014002, 2010.

Fan, X., Chen, H., Goloub, P., Xia, X., Zhang, W., and Chatenet, B.: Analysis of column-integrated aerosol optical thickness in Beijing from AERONET observations, China Particuol., 4, 330-335, https://doi.org/10.1016/S1672-2515(07)60285-1, 2006.

Giles, D. M., Holben, B. N., Eck, T. F., Sinyuk, A., Smirnov, A., Slutsker, I., Dickerson, R. R., Thompson, A. M., and Schafer, J. S.: An analysis of AERONET aerosol absorption properties and classifications representative of aerosol source regions, J. Geophys. Res.-Atmos., 117, 127-135, https://doi.org/10.1029/2012JD018127, 2012.

Giles, D. M., Sinyuk, A., Sorokin, M. G., Schafer, J. S., Smirnov, A., Slutsker, I., Eck, T. F., Holben, B. N., Lewis, J. R., Campbell, J. R., Welton, E. J., Korkin, S. V., and Lyapustin, A. I.: Advancements in the Aerosol Robotic Network (AERONET) Version 3 database - automated near-real-time quality control algorithm with improved cloud screening for Sun photometer aerosol optical depth (AOD) measurements, Atmos. Meas. Tech., 12, 169209, https://doi.org/10.5194/amt-12-169-2019, 2019.

Heald, C. L., Ridley, D. A., Kroll, J. H., Barrett, S. R. H., Cady-Pereira, K. E., Alvarado, M. J., and Holmes, C. D.: Contrasting the direct radiative effect and direct radiative forcing of aerosols, Atmos. Chem. Phys., 14, 5513-5527, https://doi.org/10.5194/acp-14-5513-2014, 2014.

Huang, J., Lin, B., Minnis, P., Wang, T., Wang, X., Hu, Y., Yi, Y., and Ayers, J. K.: Satellite-based assessment of possible dust aerosols semi-direct effect on cloud water path over East Asia, Geophys. Res. Lett., 33, L19802, https://doi.org/10.1029/2006g1026561, 2006a.

Huang, J., Minnis, P., Lin, B., Wang, T., Yi, Y., Hu, Y., SunMack, S., and Ayers, K.: Possible influences of Asian dust aerosols on cloud properties and radiative forcing observed from MODIS and CERES, Geophys. Res. Lett., 33, L06824, https://doi.org/10.1029/2005gl024724, 2006b.

Huang, J., Minnis, P., Yi, Y., Tang, Q., Wang, X., Hu, Y., Liu, Z., Ayers, K., Trepte, C., and Winker, D.: Summer dust aerosols detected from CALIPSO over the Tibetan Plateau, Geophys. Res. Lett., 34, 529-538, https://doi.org/10.1029/2007gl029938, 2007.

IPCC: Climate Change 2013: The Physical Science Basis, in: Contribution of Working Group I to the Fifth Assessment Report of the Intergovernmental Panel on Climate Change, Cambridge University Press, Cambridge, UK and New York, NY, USA, 1535 pp., 2013.

Jia, R., Liu, Y., Chen, B., Zhang, Z., and Huang, J.: Source and transportation of summer dust over the Tibetan Plateau, Atmos. Environ., 123, 210-219, https://doi.org/10.1016/j.atmosenv.2015.10.038, 2015.
Jia, R., Liu, Y., Hua, S., Zhu, Q., and Shao, T.: Estimation of the Aerosol Radiative Effect over the Tibetan Plateau Based on the Latest CALIPSO Product, J. Meteorol. Res., 32, 707-722, https://doi.org/10.1007/s13351-018-8060-3, 2018.

Jia, R., Luo, M., Liu, Y., Zhu, Q., Hua, S., Wu, C., and Shao, T.: Anthropogenic Aerosol Pollution over the Eastern Slope of the Tibetan Plateau, Adv. Atmos. Sci., 36, 847-862, https://doi.org/10.1007/s00376-019-8212-0, 2019.

Kopacz, M., Mauzerall, D., Wang, J., Leibensperger, E., Henze, D., and Singh, K.: Origin and radiative forcing of black carbon transported to the Himalayas and Tibetan Plateau, Atmos. Chem. Phys., 11, 2837-2852, https://doi.org/10.5194/acp-112837-2011, 2011.

Kumar, A., Singh, N., Anshumali, and Solanki, R.: Evaluation and utilization of MODIS and CALIPSO aerosol retrievals over a complex terrain in Himalaya, Remote Sens. Environ., 206, 139155, https://doi.org/10.1016/j.rse.2017.12.019, 2018.

Lau, K. M., Kim, M. K., and Kim, K. M.: Asian summer monsoon anomalies induced by aerosol direct forcing: the role of the Tibetan Plateau, Clim. Dynam., 26, 855-864, https://doi.org/10.1007/s00382-006-0114-z, 2006.

Lee, W.-S., Bhawar, R. L., Kim, M.-K., and Sang, J.: Study of aerosol effect on accelerated snow melting over the Tibetan Plateau during boreal spring, Atmos. Environ., 75, 113-122, https://doi.org/10.1016/j.atmosenv.2013.04.004, 2013.

Levy, R. C., Mattoo, S., Munchak, L. A., Remer, L. A., Sayer, A. M., Patadia, F., and Hsu, N. C.: The Collection 6 MODIS aerosol products over land and ocean, Atmos. Meas. Tech., 6, 29893034, https://doi.org/10.5194/amt-6-2989-2013, 2013.

Li, J., Huang, J., Stamnes, K., Wang, T., Lv, Q., and Jin, H.: A global survey of cloud overlap based on CALIPSO and CloudSat measurements, Atmos. Chem. Phys., 15, 519-536, https://doi.org/10.5194/acp-15-519-2015, 2015.

Li, J., Lv, Q., Zhang, M., Wang, T., Kawamoto, K., Chen, S., and Zhang, B.: Effects of atmospheric dynamics and aerosols on the fraction of supercooled water clouds, Atmos. Chem. Phys., 17, 1847-1863, https://doi.org/10.5194/acp-17-1847-2017, 2017.

Li, J., Jian, B., Huang, J., Hu, Y., Zhao, C., Kawamoto, K., Liao, $\mathrm{S}$., and $\mathrm{Wu}, \mathrm{M}$.: Long-term variation of cloud droplet number concentrations from space-based Lidar, Remote Sens. Environ., 213, 144-161, https://doi.org/10.1016/j.rse.2018.05.011, 2018.

Li, M., Zhang, Q., Streets, D. G., He, K. B., Cheng, Y. F., Emmons, L. K., Huo, H., Kang, S. C., Lu, Z., Shao, M., Su, H., Yu, X., and Zhang, Y.: Mapping Asian anthropogenic emissions of non-methane volatile organic compounds to multiple chemical mechanisms, Atmos. Chem. Phys., 14, 5617-5638, https://doi.org/10.5194/acp-14-5617-2014, 2014.

Liu, Y., Huang, J., Shi, G., Takamura, T., Khatri, P., Bi, J., Shi, J., Wang, T., Wang, X., and Zhang, B.: Aerosol optical properties and radiative effect determined from sky-radiometer over Loess Plateau of Northwest China, Atmos. Chem. Phys., 11, 1145511463, https://doi.org/10.5194/acp-11-11455-2011, 2011.

Liu, Y., Jia, R., Dai, T., Xie, Y., and Shi, G.: A review of aerosol optical properties and radiative effects, J. Meteorol. Res., 28, 10031028, https://doi.org/10.1007/s13351-014-4045-z, 2014.

Liu, Y., Sato, Y., Jia, R., Xie, Y., Huang, J., and Nakajima, T.: Modeling study on the transport of summer dust and anthropogenic aerosols over the Tibetan Plateau, Atmos. Chem. 
Phys., 15, 12581-12594, https://doi.org/10.5194/acp-15-125812015, 2015.

Liu, Y., Hua, S., Jia, R., and Huang, J.: Effect of Aerosols on the Ice Cloud Properties Over the Tibetan Plateau, J. Geophys. Res.Atmos., 124, 9594-9608, https://doi.org/10.1029/2019jd030463, 2019a.

Liu, Y., Zhu, Q., Huang, J., Hua, S., and Jia, R.: Impact of dust-polluted convective clouds over the Tibetan Plateau on downstream precipitation, Atmos. Environ., 209, 67-77, https://doi.org/10.1016/j.atmosenv.2019.04.001, 2019 b.

Liu, Z., Liu, D., Huang, J., Vaughan, M., Uno, I., Sugimoto, N., Kittaka, C., Trepte, C., Wang, Z., Hostetler, C., and Winker, D.: Airborne dust distributions over the Tibetan Plateau and surrounding areas derived from the first year of CALIPSO lidar observations, Atmos. Chem. Phys., 8, 5045-5060, https://doi.org/10.5194/acp8-5045-2008, 2008.

Lu, Z., Streets, D. G., Zhang, Q., and Wang, S.: A novel backtrajectory analysis of the origin of black carbon transported to the Himalayas and Tibetan Plateau during 1996-2010, Geophys. Res. Lett., 39, L01809, https://doi.org/10.1029/2011g1049903, 2012.

Ma, Y., Li, Z., Li, Z., Xie, Y., Fu, Q., Li, D., Zhang, Y., Xu, H., and Li, K.: Validation of MODIS Aerosol Optical Depth Retrieval over Mountains in Central China Based on a SunSky Radiometer Site of SONET, Remote Sens.-Basel, 8, 111, https://doi.org/10.3390/rs8020111, 2016.

Martin, R. V., Jacob, D. J., Yantosca, R. M., Chin, M., and Ginoux, P.: Global and regional decreases in tropospheric oxidants from photochemical effects of aerosols, J. Geophys. Res.-Atmos., 108, 4097, https://doi.org/10.1029/2002jd002622, 2003.

Pan, L., Che, H., Geng, F., Xia, X., Wang, Y., Zhu, C., Chen, M., Gao, W., and Guo, J.: Aerosol optical properties based on ground measurements over the Chinese Yangtze Delta Region, Atmos. Environ., 44, 2587-2596, https://doi.org/10.1016/j.atmosenv.2010.04.013, 2010.

Qian, Y., Flanner, M. G., Leung, L. R., and Wang, W.: Sensitivity studies on the impacts of Tibetan Plateau snowpack pollution on the Asian hydrological cycle and monsoon climate, Atmos. Chem. Phys., 11, 1929-1948, https://doi.org/10.5194/acp11-1929-2011, 2011.

Sayer, A. M., Munchak, L. A., Hsu, N. C., Levy, R. C., Bettenhausen, C., and Jeong, M. J.: MODIS Collection 6 aerosol products: Comparison between Aqua's e-Deep Blue, Dark Target, and "merged" data sets, and usage recommendations, J. Geophys. Res.-Atmos., 119, 13965-13989, https://doi.org/10.1002/2014jd022453, 2014.

Shen, R. Q., Ding, X., He, Q. F., Cong, Z. Y., Yu, Q. Q., and Wang, X. M.: Seasonal variation of secondary organic aerosol tracers in Central Tibetan Plateau, Atmos. Chem. Phys., 15, 8781-8793, https://doi.org/10.5194/acp-15-8781-2015, 2015.

Takemura, T., Nozawa, T., Emori, S., Nakajima, T. Y., and Nakajima, T.: Simulation of climate response to aerosol direct and indirect effects with aerosol transport-radiation model, J. Geophys. Res., 110, D02202, https://doi.org/10.1029/2004jd005029, 2005.

Tobo, Y., Iwasaka, Y., Shi, G.-Y., Kim, Y.-S., Ohashi, T., Tamura, K., and Zhang, D.: Balloon-borne observations of high aerosol concentrations near the summertime tropopause over the Tibetan Plateau, Atmos. Res., 84, 233-241, https://doi.org/10.1016/j.atmosres.2006.08.003, 2007. van der Werf, G. R., Randerson, J. T., Giglio, L., Collatz, G. J., Mu, M., Kasibhatla, P. S., Morton, D. C., DeFries, R. S., Jin, Y., and van Leeuwen, T. T.: Global fire emissions and the contribution of deforestation, savanna, forest, agricultural, and peat fires (1997-2009), Atmos. Chem. Phys., 10, 11707-11735, https://doi.org/10.5194/acp-10-11707-2010, 2010.

Wan, X., Kang, S., Wang, Y., Xin, J., Liu, B., Guo, Y., Wen, T., Zhang, G., and Cong, Z.: Size distribution of carbonaceous aerosols at a high-altitude site on the central Tibetan Plateau (Nam Co Station, 4730 m a.s.1.), Atmos. Res., 153, 155-164, https://doi.org/10.1016/j.atmosres.2014.08.008, 2015.

Wang, P., Che, H. Z., Zhang, X. C., Song, Q. L., Wang, Y. Q., Zhang, Z. H., Dai, X., and Yu, D. J.: Aerosol optical properties of regional background atmosphere in Northeast China, Atmos. Environ., 44, 4404-4412, https://doi.org/10.1016/j.atmosenv.2010.07.043, 2010.

Wang, X., Ren, J., Gong, P., Wang, C., Xue, Y., Yao, T., and Lohmann, R.: Spatial distribution of the persistent organic pollutants across the Tibetan Plateau and its linkage with the climate systems: a 5-year air monitoring study, Atmospheric Chemistry and Physics, 16, 6901-6911, https://doi.org/10.5194/acp16-6901-2016, 2016.

Wang, Y. X., McElroy, M. B., Jacob, D. J., and Yantosca, R. M.: A nested grid formulation for chemical transport over Asia: Applications to CO, J. Geophys. Res.-Atmos., 109, D22307, https://doi.org/10.1029/2004jd005237, 2004.

Winker, D. M., Pelon, J., Coakley, J. A., Ackerman, S. A., Charlson, R. J., Colarco, P. R., Flamant, P., Fu, Q., Hoff, R. M., Kittaka, C., Kubar, T. L., Le Treut, H., McCormick, M. P., Megie, G., Poole, L., Powell, K., Trepte, C., Vaughan, M. A., and Wielicki, B. A.: THE CALIPSO MISSION A Global 3D View of Aerosols and Clouds, B. Am. Meteorol. Soc., 91, 1211-1229, https://doi.org/10.1175/2010bams3009.1, 2010.

Xia, X., Che, H., Zhu, J., Chen, H., Cong, Z., Deng, X., Fan, X., Fu, Y., Goloub, P., Jiang, H., Liu, Q., Mai, B., Wang, P., Wu, Y., Zhang, J., Zhang, R., and Zhang, X.: Ground-based remote sensing of aerosol climatology in China: Aerosol optical properties, direct radiative effect and its parameterization, Atmos. Environ., 124, 243-251, https://doi.org/10.1016/j.atmosenv.2015.05.071, 2016.

Xia, X. G., Wang, P. C., Wang, Y. S., Li, Z. Q., Xin, J. Y., Liu, J., and Chen, H. B.: Aerosol optical depth over the Tibetan Plateau and its relation to aerosols over the Taklimakan Desert, Geophys. Res. Lett., 35, 96-106, https://doi.org/10.1029/2008g1034981, 2008.

Xia, X. G., Zong, X. M., Cong, Z. Y., Chen, H. B., Kang, S. C., and Wang, P. C.: Baseline continental aerosol over the central Tibetan plateau and a case study of aerosol transport from South Asia, Atmos. Environ., 45, 7370-7378, https://doi.org/10.1016/j.atmosenv.2011.07.067, 2011.

Xin, J. Y., Wang, Y. S., Li, Z. Q., Wang, P. C., Hao, W. M., Nordgren, B. L., Wang, S. G., Liu, G. R., Wang, L. L., Wen, T. X., Sun, Y., and Hu, B.: Aerosol optical depth (AOD) and Angstrom exponent of aerosols observed by the Chinese Sun Hazemeter Network from August 2004 to September 2005, J. Geophys. Res.Atmos., 112, 1703-1711, https://doi.org/10.1029/2006jd007075, 2007.

Xing, C., Liu, C., Wang, S., Chan, K. L., Gao, Y., Huang, X., Su, W., Zhang, C., Dong, Y., Fan, G., Zhang, T., Chen, Z., Hu, Q., Su, H., 
Xie, Z., and Liu, J.: Observations of the vertical distributions of summertime atmospheric pollutants and the corresponding ozone production in Shanghai, China, Atmos. Chem. Phys., 17, 1427514289, https://doi.org/10.5194/acp-17-14275-2017, 2017.

Yang, R., Wang, J., Zhang, T., and He, S.: Change in the relationship between the Australian summer monsoon circulation and boreal summer precipitation over Central China in the late 1990s, Meteorol. Atmos. Phys., 131, 105-113, https://doi.org/10.1007/s00703-017-0556-3, 2017a.

Yang, R. W., Tao, Y., and Cao, J.: A Mechanism for the Interannual Variation of the Early Summer East Asia-Pacific Teleconnection Wave Train, Acta Meteorol. Sin., 24, 452-458, 2010.

Yang, Y., Russell, L. M., Lou, S., Liao, H., Guo, J., Liu, Y., Singh, B., and Ghan, S. J.: Dust-wind interactions can intensify aerosol pollution over eastern China, Nat. Commun., 8, 15333, https://doi.org/10.1038/ncomms15333, 2017b.

Zhang, B., Wang, Y., and Hao, J.: Simulating aerosol-radiationcloud feedbacks on meteorology and air quality over eastern China under severe haze conditionsin winter, Atmos. Chem. Phys., 15, 2387-2404, https://doi.org/10.5194/acp-152387-2015, 2015.

Zhang, N., Cao, J., Ho, K., and He, Y.: Chemical characterization of aerosol collected at Mt. Yulong in wintertime on the southeastern Tibetan Plateau, Atmos. Res., 107, 76-85, https://doi.org/10.1016/j.atmosres.2011.12.012, 2012.

Zhang, X. Y., Arimoto, R., Cao, J. J., An, Z. S., and Wang, D.: Atmospheric dust aerosol over the Tibetan Plateau, J. Geophys. Res.-Atmos., 106, 18471-18476, https://doi.org/10.1029/2000jd900672, 2001.

Zhao, Z., Cao, J., Shen, Z., Xu, B., Zhu, C., Chen, L. W. A., Su, X., Liu, S., Han, Y., Wang, G., and Ho, K.: Aerosol particles at a high-altitude site on the Southeast Tibetan Plateau, China: Implications for pollution transport from South Asia, J. Geophys. Res.-Atmos., 118, 11360-311375, https://doi.org/10.1002/jgrd.50599, 2013.
Zhu, J., Che, H., Xia, X., Chen, H., Goloub, P., and Zhang, W.: Column-integrated aerosol optical and physical properties at a regional background atmosphere in North China Plain, Atmos. Environ., 84, 54-64, https://doi.org/10.1016/j.atmosenv.2013.11.019, 2014.

Zhu, J., Xia, X., Che, H., Wang, J., Zhang, J., and Duan, Y.: Study of aerosol optical properties at Kunming in southwest China and long-range transport of biomass burning aerosols from North Burma, Atmos. Res., 169, 237-247, https://doi.org/10.1016/j.atmosres.2015.10.012, 2016.

Zhu, J., Xia, X., Wang, J., Zhang, J., Wiedinmyer, C., Fisher, J. A., and Keller, C. A.: Impact of Southeast Asian smoke on aerosol properties in Southwest China: First comparison of model simulations with satellite and ground observations, J. Geophys. Res.Atmos., 122, 3904-3919, https://doi.org/10.1002/2016jd025793, 2017.

Zhu, Q., Liu, Y., Jia, R., Hua, S., Shao, T., and Wang, B.: A numerical simulation study on the impact of smoke aerosols from Russian forest fires on the air pollution over Asia, Atmos. Environ., 182, 263-274, https://doi.org/10.1016/j.atmosenv.2018.03.052, 2018.

Zhuang, B. L., Wang, T. J., Liu, J., Li, S., Xie, M., Han, Y., Chen, P. L., Hu, Q. D., Yang, X. Q., Fu, C. B., and Zhu, J. L.: The surface aerosol optical properties in the urban area of Nanjing, west Yangtze River Delta, China, Atmos. Chem. Phys., 17, 11431160, https://doi.org/10.5194/acp-17-1143-2017, 2017.

Zhuang, B. L., Wang, T. J., Liu, J. N. E., Che, H. Z., Han, Y., Fu, Y., Li, S., Xie, M., Li, M. M., Chen, P. L., Chen, H. M., Yang, X. Q., and Sun, J. N.: The optical properties, physical properties and direct radiative forcing of urban columnar aerosols in the Yangtze River Delta, China, Atmos. Chem. Phys., 18, 14191436, https://doi.org/10.5194/acp-18-1419-2018, 2018. 